University of Rhode Island

DigitalCommons@URI

Open Access Master's Theses

2012

\title{
THE PROCESS OF MAKING AMENDS IN THE ALCOHOLICS ANONYMOUS PROGRAM: A QUALITATIVE STUDY
}

Allison Seperack

University of Rhode Island, allisonkgarris@gmail.com

Follow this and additional works at: https://digitalcommons.uri.edu/theses

\section{Recommended Citation}

Seperack, Allison, "THE PROCESS OF MAKING AMENDS IN THE ALCOHOLICS ANONYMOUS PROGRAM: A QUALITATIVE STUDY" (2012). Open Access Master's Theses. Paper 113.

https://digitalcommons.uri.edu/theses/113

This Thesis is brought to you for free and open access by DigitalCommons@URI. It has been accepted for inclusion in Open Access Master's Theses by an authorized administrator of DigitalCommons@URI. For more information, please contact digitalcommons-group@uri.edu. 
THE PROCESS OF MAKING AMENDS IN THE

ALCOHOLICS ANONYMOUS PROGRAM:

A QUALITATIVE STUDY

BY

ALLISON SEPERACK

A THESIS SUBMITTED IN PARTIAL FULFILLMENT OF THE

REQUIREMENTS FOR THE DEGREE OF

MASTER OF SCIENCE

IN

HUMAN DEVELOPMENT AND FAMILY STUDIES

UNIVERSITY OF RHODE ISLAND 
MASTER OF SCIENCE THESIS

OF

ALLISON SEPERACK

\section{APPROVED:}

Thesis Committee: Dr. Barbara M. Newman

Dr. Mark E. Wood

Major Professor: Dr. Phillip G. Clark

DEAN OF THE GRADUATE SCHOOL

Nasser H. Zawia

UNIVERSITY OF RHODE ISLAND

2012 


\begin{abstract}
This study explored the process of making amends in the A.A. program, specifically the effects that good and bad amends have on sobriety. Six A.A. members were recruited and participated in 30-50 minute long individual interviews to discuss the effects of good and bad amends. Interviews were transcribed and coded and five themes were developed. The fear of responsibility described the in-depth and fearful process participants underwent in admitting to past harms. Second chances at healthy relationships described the positive influences the good amends had on the self, the Higher Power, and the person to whom the amends were made. Transcending the harm explained the trauma done to the self, the Higher Power, and the other, which after a period of reflection allowed the alcoholic to transcend the damage and move on. Freedom from past behaviors described the feeling of serenity participants felt from the amends and their dedication to living a new life that no longer included their past destructive behaviors. Lastly, participants revealed the importance of a sponsor as one of the most crucial indicators for success in the A.A. program. While forgiveness was initially thought to be a central part of the amends process, findings revealed that the process of making amends does not require reconciling the relationship with others, a central concept of forgiveness. Future research should expand on the variables used to measure A.A. program success to include various aspects surrounding the quality of sobriety, rather than quantifiable variables that measure only abstinence.
\end{abstract}




\section{ACKNOWLEDGEMENTS}

First, thank you to my Dad, for teaching me that being successful means never giving up; and thank you to my Mom, who taught me to do my best, no matter what.

This paper would not have been possible without the help of Dr. Phillip Clark and his ageless Swiss Cheese model. Thank you for always taking the time to meet,

read, and edit this thesis. Your dedication to this project has made all the difference, and I truly appreciate your help. Thank you so much.

Thank you to my committee members, Dr. Barbara Newman and Dr. Mark Wood, for taking on the extra work to assist in this thesis and giving me the added guidance I needed in writing it.

Thank you to Meada Daly-Cano, who took time out of her busy schedule to read and code my interviews. I've never been more grateful to have someone who disagrees with me. Thank you for your insights on this thesis.

Thank you to Dr. Karen McCurdy, for being such a great role model and mentor throughout my graduate career. You've helped me succeed greatly.

Thank you to my best friend and fiancé, Jacob, who is always there to make me laugh and inspire me. You're the best, and I couldn't have done it without you. I love you!

Finally, thank you to all of my participants, who did the best $12^{\text {th }}$ Step I could ask for. I am so grateful to all of you for your time and experiences, which made this paper possible. Keep comin', it works! 


\section{DEDICATION}

This paper is dedicated to my grandparents: Herman and Rita, and Frank and Millie. 


\section{TABLE OF CONTENTS}

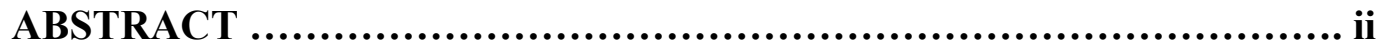

ACKNOWLEDGEMENTS $\ldots \ldots \ldots \ldots \ldots \ldots \ldots \ldots \ldots \ldots \ldots \ldots \ldots \ldots \ldots \ldots \ldots \ldots \ldots \ldots$ iii

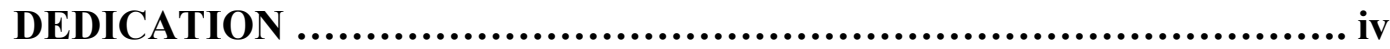

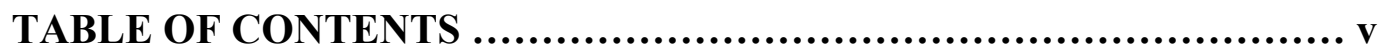

CHAPTER 1

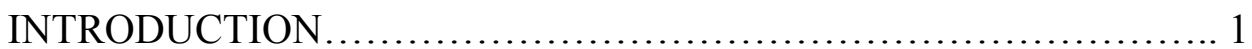

\section{CHAPTER 2}

REVIEW OF LITERATURE....................................... 2

\section{CHAPTER 3}

METHODOLOGY

\section{CHAPTER 4}

FINDINGS

26

CHAPTER 5

DISCUSSION 44

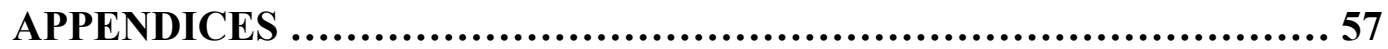

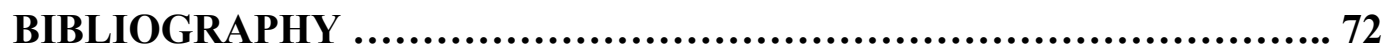




\section{CHAPTER 1}

\section{INTRODUCTION}

This study explores the experience that participants in the Alcoholics Anonymous (A.A.) program encounter during the process of making amends to those persons they have harmed as a result of their addiction. Interviews sought to understand the full range of circumstances, emotions, and coping abilities that an alcoholic experiences during this step in recovery. This exploratory analysis investigates the process of seeking forgiveness and adds to the knowledge in this area of research.

Alcoholics Anonymous (A.A.), a recovery program for alcoholic men and women, was established in 1935 by Dr. Bob Silkworth and Bill Wilson in Akron, Ohio, and is known to be one of the earliest forms of self-help groups (Alcoholics Anonymous, 2010; McCrady, Horvath, \& Delaney, 2003). A.A.'s numbers have grown increasingly over the past 77 years with membership reaching over 1 million in the U.S. and approaching 1 million in Canada (A.A. Fact File, 2010). As stated in the Twelve Traditions of A.A., a description of the functionality of the program, the only requirement for membership is a desire to stay sober (Alcoholics Anonymous, 2010). The 12 steps (see Appendix A) outline specific instructions on how to stay sober, and include various directives such as admitting powerlessness over alcohol, taking a personal inventory, accepting a Higher Power, making amends, and serving others in and outside the program (Alcoholics Anonymous, 2010). 


\section{CHAPTER 2}

\section{REVIEW OF LITERATURE}

\section{Introduction}

The following sections will review the literature related to A.A. in terms of variables that have been seen as important to the program. These variables are relevant to this study, as many of them have great implications for the process of making amends. Understanding in what ways these variables may affect an alcoholic's sobriety is important to this study. Alternate alcoholic self-help groups will also be discussed, in terms of their programmatic differences from A.A.

\section{Variables Related to A.A. Success and Related Terminology}

When evaluating the successfulness of A.A., many studies have measured efficacy in the program in various ways, the most popular being length of time alcoholics have refrained from drinking (Gabhainn, 2003; Gomes \& Hart, 2009; Kaskutas, Turk, Bond, \& Weisner, 2003; Morgenstern, Labouvie, McCrady, Kahler, \& Frey, 1997; Oakes, Allen, \& Ciarrocchi, 2000; Tonigan \& Rice, 2010; Webb, Robinson, Brower, \& Zucker, 2006; Webb, Robinson, \& Brower, 2009; Zemore, 2007). Studies have come to define success as abstinence or sobriety, or used the terms interchangeably (Gabhainn, 2003; Kaskutas et al., 2003; Majer, Jason, Ferrari, \& Miller, 2011; Morgenstern et al., 1997; Oakes et al., 2000; Pagano et al., 2009; Robinson, Cranford, Webb, \& Brower, 2007; Tonigan \& Rice, 2010; Zemore, 2007). Alcoholics Anonymous does not explicitly make a distinction between the 
terms abstinence and sobriety, but does seem to suggest that sobriety is both the act of abstaining from alcohol, and working the 12-Steps (Alcoholics Anonymous, 2010). Frequent references are made to refraining from alcohol, but A.A. also recognizing that this is only the first step, and that a much more intensive journey must be made to continue on this path (Alcoholics Anonymous, 2010).

This section discusses on the most widely used variables that are used to characterize A.A. efficacy, which includes both abstinence and sobriety.

\section{A.A. involvement.}

A.A. involvement has most commonly come to be defined as the number of meetings an alcoholic attends (Kaskutas et al., 2003; Oakes et al., 2000), having a sponsor or being a sponsor (Kaskutas et al., 2003; Oakes et al., 2000; Pagano, Zeltner, Jaber, Post, Zywiak, \& Stout, 2009), reading A.A. literature (Kaskutas et al., 2003; Morgenstern et al, 1997), providing service to members (Pagano et al., 2009), completing the steps (Oakes et al., 2000), and participating in step meetings and A.A. activities (Gomes \& Hart, 2009; Morgenstern et al., 1997). A.A. involvement and its relationship to length of sobriety have therefore been of interest, and, when studied, have been found to have a linear relationship (Kaskutas et al., 2003; Zemore, 2007), as do decreases in A.A. involvement and length of sobriety (Zemore, 2007). Notably, one of Gomes and Hart's (2009) items used to describe A.A. involvement was completing steps 4 and 5, the first two steps in the amends process and an important focus of this study. Findings indicated that of the 76 participants surveyed, those who completed steps 4 and 5 were almost five times less likely to relapse. In terms of 
overall emotional wellbeing, completion of steps 4 and 5 also negatively predicted depression and anxiety (Gomes \& Hart, 2009).

Oakes et al. (2000) used three measures to survey three outcomes, which included drinking status, drinking consequences, and days abstinent. In addition, they utilized five measures for the predictor variables, which were religious-problem solving styles, spiritual support and openness, religious practice, meaning in life, and A.A. involvement (Oakes et al., 2000). Seventy-eight alcoholics were surveyed and logistic regression results indicated that A.A. involvement was the strongest predictor of length of sobriety in contrast to the religious variables (Oakes et al., 2000).

Morgenstern et al. (1997) surveyed a sample of 100 alcoholics who were entering into a residential or intensive day treatment facility. The relationship between substance use and A.A. affiliation was investigated. A.A. affiliation was defined by nine behaviors, mostly notably the degree to which a person's life was centered on A.A. activities. Multiple regression results indicated that an overall increased involvement in A.A. was predictive of sustained abstinence from alcohol.

\section{Spiritual awakening.}

Another interest in the variables related to abstinence is that of a spiritual awakening. The Big Book, the affectionate name used by A.A. members to describe their handbook, Alcoholics Anonymous, mentions the intervention of an individual's Higher Power in six of the 12 Steps and explains the importance of turning one's will and life over to their Higher Power (Alcoholics Anonymous, 2010). Numerous studies have tried to measure this concept in various ways. Kaskutas et al. (2003) surveyed 587 alcoholics at baseline, one year, and three years, and asked participants 
to define their religiosity as atheist, agnostic, unsure, spiritual, or religious.

Participants were also asked if they had experienced a spiritual awakening since becoming a member of A.A. (Kaskutas et al., 2003). What constitutes a spiritual awakening was not defined; participants were simply asked to indicate whether they had experienced one at three different times (Kaskutas et al., 2003).

Results showed that by time three, those participants identifying themselves as religious $(27 \%)$ or spiritual $(21 \%)$ reported a 5\%-6\% increase in experiencing a spiritual awakening, while participants identifying themselves as unsure reported a $13 \%$ increase in spiritual awakenings (Kaskutas et al., 2003). This is interesting to note considering that those who had some sort of spiritual connection reported fewer spiritual awakenings.

Additionally, increased spiritual experiences have been positively associated with abstinence at six months (Robinson, Cranford, Webb, \& Brower, 2007) and 12 months (Zemore, 2007). Spirituality has also been shown to influence problemsolving behavior in alcoholics and is another factor linked to prolonged sobriety (Oakes et. al, 2000). Understanding the relationship an alcoholic develops with a Higher Power is an important focus for this study.

\section{Helping in A.A.}

Of further interest in regard to the variables that influence sustained sobriety, Pagano et al. (2009) looked at helping behaviors among alcoholics in A.A. Participants rated how often they helped others at home, work, and within 12-Step programs and how much their helping behaviors affected their sobriety (Pagano et al., 2009). Results indicated that helping others in 12-Step programs was linked to a 
greater effect on sobriety, which highlights the $12^{\text {th }}$ step of A.A., or service to others, in the program (Alcoholics Anonymous, 2010; Pagano et al., 2009). Additionally, engaging in these activities also appears correlated with an increase in a person's selfefficacy, contributing to their consistent abstinence (Majer, Jason, Ferrari, \& Miller, 2011).

It is also important to note that on the sociodemographic/clinical characteristics assessments done at the intake of this study, $45 \%$ of participants rated the $4^{\text {th }}$ step as the most difficult of the 12 Steps to complete (Pagano et al., 2009). Although this does not describe service in A.A., it does describe the first step in the amends process, which this study will explore in more detail.

\section{Sponsor.}

Tonigan and Rice (2010) looked at the longitudinal benefits of having a sponsor in A.A., by surveying the degree to which alcoholics practice the 12 Steps and whether they currently had a sponsor. The scale included items such as sharing their personal inventory and meditating, which describe step 5 and possibly step 6 , respectively (Alcoholics Anonymous, 2010; Tonigan \& Rice, 2010). Hierarchical linear regression results indicated that having a sponsor predicted sobriety, for as much as 4 to 6 months after baseline, and it also increased the probability of abstinence by three times (Tonigan \& Rice, 2010).

\section{Perceived success in A.A.}

Gabhainn (2003) cross-sectionally investigated how perceived and attained sobriety were assessed and described by 77 members of A.A. with one-year sobriety in the United Kingdom. Participants described three clear categories of program success, 
including taking it "one day at a time," staying sober for the long term, and the quality of sobriety (Gabhainn, 2003). Importantly, those who described quality as an indicator of success were considered to be more stable A.A. members (Gabhainn, 2003). Quality came to be defined by participants as finding a sense of peace, serenity, honesty, and feeling connected to other A.A. members (Gabhainn, 2003). Gabhainn's (2003) findings suggest a new approach to change testing success in A.A., in which sobriety can be measured by investigating how quality of sobriety is defined and what it entails. The present study explores this question in more depth.

\section{Alternative Alcoholic Self-help Groups}

Although A.A. is one of the oldest self-help groups, it is certainly not the only one (McCrady et al., 2003). Alternative self-help groups will be discussed as understanding the different approaches used to achieve sobriety provides a comparison for A.A. efficacy.

\section{Self-management and training recovery.}

The self-management and recovery training (SMART) program uses only methods that are shown to be empirically effective practices as a way to stay sober, such as cognitive behavior therapy (McCrady et al., 2003). Similar to A.A., meetings are held where alcohol-related experiences and urges are discussed, but the use of a Higher Power is optional (McCrady et al., 2003). SMART allows the participant to develop a plan for staying sober, as well as a reflection on how their recovery influences their social roles rather than delegating specific steps for sobriety (McCrady et al., 2003). 
For some alcoholics, A.A.'s emphasis on developing a relationship with a Higher Power is a barrier, and so other alternative groups such as SMART are sought out (Atkins \& Hawdon, 2007). However, in a sample of 81 alcoholics involved in SMART or A.A., $48 \%$ of the SMART participants surveyed were found to believe in a Higher Power, as compared to $96 \%$ of the A.A. members (Li, Feifer, \& Strohm, 2000). Additionally, in looking at the relationship between program participation in SMART and the role of a Higher Power, results indicated a negative relation, signaling that SMART participants did not feel as though they needed a religious aspect in order to participate in their program (Atkins \& Hawdon, 2007). In fact, $40.6 \%$ of SMART participants agreed that religiousness and spirituality were two different constructs, and $86.3 \%$ of SMART participants believed A.A. was inherently religious (Atkins \& Hawdon, 2007).

Atkins and Hawdon (2007) assert that the distinction between religious and spiritual may be an important factor in choosing a self-help group, as those who are not looking for religiousness may be more inclined to join a group that is perceived to be spiritual. Unfortunately, Atkins and Hawdon (2007) do not discuss how spirituality is defined in their paper and how it is different from religiosity, only that many people believe A.A. to be more religious in nature than spiritual (Atkins \& Hawdon, 2007). This is a bit of a concern, as their measures surveyed spirituality, but they neglected to define or describe how that might be different than religiousness.

Another study compared 12-Step programs, such as A.A. and Narcotics Anonymous (N.A.), and SMART by alternately assigning participants to one of two intervention groups. The intervention consisted of practicing either 12-Step or 
SMART program guidelines for 6 months (Brooks \& Penn, 2003). Assessments occurred at baseline, 3 , and 6 months during treatment, as well as 3 and 12 months after treatment (Brooks \& Penn, 2003). SMART was found to be less effective than 12-Step programs in maintaining sobriety, but it improved health and employment conditions (Brooks \& Penn, 2003). However, both programs were found to improve life satisfaction (Brooks \& Penn, 2003).

\section{Women for Sobriety.}

Women for Sobriety (WFS) was created to counteract the emphasis on powerlessness, a Higher Power, and negative experiences found in A.A. (McCrady et al., 2003). WFS has many distinctions from A.A. in that women are encouraged to take personal control rather than rely on a Higher Power, to identify themselves as recovering women rather than as alcoholics, and that discontinuation of the program is possible once a woman feels she is able to cope independently with her addiction (McCrady et al., 2003).

Investigating the argument that A.A. is not sensitive to women's' needs, a post hoc analysis of longitudinal data on 276 alcoholic men and women found that not only was there a significant association between A.A. membership and sobriety at both 1.52.5 years and 2.5-3.0 years, but that A.A. members were four times more likely to be sober at 2.5-3.0 years (Krentzman, Brower, Cranford, Bradley, \& Robinson, 2011). Additionally, women were also four times more likely than men to be sober at 2.5-3.0 years if they were A.A. members at 1.5 years (Krentzman et al., 2011). In regards to the criticism WFS has on the construct of a Higher Power, 32\% of WFS participants rated 12-Step programs as spiritual and not religious, an interesting finding 
considering that SMART's criticism of A.A. is that it is more religious than spiritual (Atkins \& Hawdon, 2007).

\section{Secular Organizations for Sobriety/Save Our Selves.}

Secular Organizations for Sobriety/Save Our Selves (SOS) sets itself apart from A.A. by its belief that religion and spirituality are separate components that do not influence sobriety, and therefore it does not endorse the acceptance of a Higher Power. However, it is the most similar self-help group to that of A.A. (McCrady et al., 2003). Like A.A., SOS believes that total abstinence from alcohol is necessary, service to others positively influences sobriety, and that the only requirement to join is a desire to stop drinking (Alcoholics Anonymous, 2010; McCrady et al., 2003).

In a sample of 158 SOS members, Connors and Dermen (1996) surveyed previous A.A. participation, as well as likes and dislikes of the A.A. program. Fortythree percent of SOS participants reported that they preferred SOS because it was not religious and $12 \%$ said that this was the most helpful aspect of the program (Connors

\& Dermen, 1996). Expectedly, 66\% disliked the religiousness of A.A. and 51\% found it to be the least helpful aspect of the program (Connors \& Dermen, 1996). Additionally, there was a negative relationship between religion and SOS participation, and more than half of SOS participants agreed that 12-Step programs were religious (Atkins \& Hawdon, 2007).

Interestingly at the time of the study, $30 \%$ of the SOS sample was simultaneously attending A.A. meetings, with $96 \%$ of participants having ever attended at least one A.A. meeting. Additionally, half of the sample reported having attended over 100 A.A. meetings, and averaged 56 A.A. meetings over the last year 
and about four A.A. meetings in the last month (Connors \& Dermen, 1996).

Compared to SOS meetings, the average number of meetings attended in the last year was 29, with about four meetings in the last month, and an average of 45 total number of SOS meetings ever attended (Connors \& Dermen, 1996). Most notably, $61 \%$ of SOS members planned not to return to A.A., and only about half of the sample found A.A. to be helpful in maintaining sobriety (Connors \& Dermen, 1996).

\section{Dimensions of Forgiveness in A.A.}

A central feature of five of the core steps in A.A. focuses on the concept of forgiveness. Little is known about the importance surrounding the steps involving forgiveness, because much of the research has focused on the 12 Steps as whole. The amends process begins in Step 4 and ends in Step 9, but comes full circle again in Step 10 (Alcoholics Anonymous, 2010). This process is learned and is then implemented in everyday life, where the alcoholic promptly admits when wrong (Alcoholics Anonymous, 2010). If the efficacy of A.A. is largely dependent on the 12 Steps and six of those steps address forgiveness, investigation of these steps is warranted.

Forgiveness in A.A. entails three dimensions. Each dimension is described below with its direct relationship to the steps.

\section{Forgiveness of self.}

Forgiveness of self occurs when an alcoholic completes Step 4, which includes the alcoholic taking a personal inventory (Alcoholics Anonymous, 2010). In this inventory (see Appendix B for personal inventory worksheets), the alcoholic will list their role in past harms they have committed to others as a result of their drinking (Alcoholics Anonymous, 2010). The alcoholic will also name their character defects 
as a way to specifically understand his/her part in the harmful behavior (Alcoholics Anonymous, 2010). The character defects include selfishness, dishonesty, selfseeking, and being frightened (Alcoholics Anonymous, 2010). Acknowledgment of these harms allows the alcoholic to take responsibility for their destructive drinking behaviors, accept responsibility for their harms, and continue sobriety (Alcoholics Anonymous, 2010).

\section{Forgiveness from a Higher Power.}

Forgiveness from a Higher Power occurs in Steps 6 and 7 and entails admission from the alcoholic to their Higher Power of their defects of character and their shortcomings (Alcoholics Anonymous, 2010). Asking a Higher Power to remove shortcomings demonstrates the alcoholic's readiness to ask their Higher Power for the acceptance of their own responsibility for their faults. Additionally, the alcoholic expresses their need to be cleansed by their Higher Power so that they can rectify their lives, which have become unmanageable from alcohol abuse (Alcoholics Anonymous, 2010). Asking for their Higher Power to intervene is thought to be the time when alcoholics experience a spiritual awakening, which, as the literature suggests, is associated with increases in sobriety (Kaskutas et al., 2003; Oakes et al., 2000; Robinson et al., 2007; Zemore, 2007). However, defining what a spiritual awakening has neglected in the literature.

\section{Forgiveness from others.}

This is the final phase of forgiveness, in which the alcoholic carries out their amends. The alcoholic combines their forgiveness from themselves and their Higher 
Power in Steps 4, 6, and 7 and is now ready to admit to their harms and demonstrate a sincere change in behavior to others in Step 9 (Alcoholics Anonymous, 2010).

The $9^{\text {th }}$ step of A.A. states that members, "Made direct amends to such people wherever possible, except when to do so would injure them or others," where "such people" describes those the alcoholic has hurt in some way as a result of their drinking (Alcoholics Anonymous, 2010, p. 59). The amends process represents a healing process for the alcoholic, where they must learn to be completely honest with themselves, others, and God; take responsibility for their offenses; and dedicate themselves to staying sober (Alcoholics Anonymous, 2010). Their seeking forgiveness is implemented through a verbal account of their offenses, coupled with a demonstrated change in behavior to stop drinking and stay sober (Alcoholics Anonymous, 2010).

\section{Forgiveness in A.A.}

In the realm of forgiveness, Webb et al. (2009) studied the relationship between forgiveness of the self, others, and God to mental health and found that higher levels of forgiveness for the self and others were associated with lower levels of mental health symptoms, such as distress. Interestingly, forgiveness by God was unrelated to mental health in three different analyses: a paired sample $t$ test and bivariate and multivariate correlational analyses (Webb et al., 2009). Webb et al. (2006) used the same three constructs of forgiveness in relation to alcohol-related variables, which included drinks per day and days abstinent. All three constructsforgiveness of self, others, and God were positively associated with percent of days abstinent and negatively with heavy drinking days (Webb et al., 2006). 
Although there is an extensive amount of research focused on helping people learn to extend forgiveness to an offender (Enright, Santos, \& Al-Mabuk, 1989; McCullough, Worhington, \& Rachal, 1997; Wade \& Worthington, 2003; Wade, Worthington, \& Haake, 2009), and treatments that teach accepting forgiveness, understanding what that process is like for those asking for forgiveness has largely been ignored in current research. Although a few studies have found that asking for forgiveness leads to psychological well-being (Krause \& Ellison, 2003; Webb, Robinson, \& Brower, 2009; Weiner, Graham, Peter, \& Zmuidinas, 1991), little attention has been paid to the implications presented in situations where forgiveness was not accepted. During an alcoholic's amends process, the alcoholic themselves or their amends may be rebuffed or rejected.

\section{Model of unforgiveness and forgiveness within ongoing relationships}

Worthington and Wade (1999) developed a model of personal, environmental, and relationship factors that can help or hinder both forgiveness and unforgiveness. In this model, forgiveness is defined as an internal process in which one makes a conscious or unconscious decision to move away from unforgiveness and reconcile the relationship (Worthington \& Wade, 1999). Reconciliation is defined as rebuilding trust in the relationship and restoring the relationship (Wade \& Worthington, 2005;

Worthington \& Wade, 1999). Alternatively, unforgiveness involves emotions such as resentment and bitterness and avoidance or retaliation against an offender (Worthington \& Wade, 1999).

In their model, Worthington and Wade (1999) describe two reactions that a victim, in this case the person the alcoholic makes their amends to, and the offender, 
the alcoholic, can exhibit. The victim may react negatively with avoidance or retaliation, or positively by reconciling the relationship (Worthington \& Wade, 1999). This describes the type of amends an alcoholic may have: one that is successful, in that the victim has accepted their amends and moves toward a relationship through forgiveness, or unsuccessfully, where they refuse the alcoholic's opportunity for an amends or choose to reject it; through unforgiveness.

The offender, based on the reaction of the victim, will also have either a positive or negative response (Worthington \& Wade, 1999). Positive responses for the offender are described as emotionally dissonant events, which are passive-aggressive attempts at reconciling, and when resolved will result in forgiveness. In contrast, a negative reaction is described as unforgiveness (Worthington \&Wade, 1999). This addresses the effect the good and bad amends may have on an alcoholic's self, Higher Power, and person they are making their amends to.

Worthington and Wade (1999) also describe the implications the offender's negative reaction may have on the victim. If the offender refuses to accept their wrongful behavior, then the victim may transform their emotions of anger and hatred, through a process called rumination, into bitterness and resentment (McCullough et al.,1997; Worthington \& Wade, 1999). Although this describes the victim, and the effect on the offender was not discussed, the Big Book would suggest a very similar path that alcoholics experience when they are actively drinking (Alcoholics Anonymous, 2010). In the section devoted to explaining the instructions on how to take an honest and thorough personal inventory, the Big Book explains: 
The first thing apparent was that this world and its people were often quite wrong. To conclude that others were wrong was as far as most of us ever got. The usual outcome was that people continued to wrong us and we stayed sore. Sometimes it was remorse and then we were sore at ourselves. But the more we fought and tried to have our own way, the worse matters got (Alcoholics Anonymous, 2010, p. 66).

This describes the alcoholic as experiencing much of what the victim in the Worthington and Wade (1999) model face, albeit pre-amends. However, it is possible that this experience still occurs, especially for alcoholics who are making amends that may be rejected.

One of the contextual points of great importance in forgiving is the positive or negative emotional valence of the relationship, or the general emotions a person feels toward the relationship (Worthington \& Wade, 1999). Valence can be changed, depending on positive or negative events, which are described as transgressions (Worthington \& Wade, 1999). Transgressions are actions that are perceived as wrong, morally offensive, cause psychological or physical harm, and are most destructive when they are repeated without apology or guilt (Worthington \& Wade, 1999). For A.A. members, their destructive behaviors and transgressions are purportedly a result of their character defects, and vice versa, where some of those character defects may prohibit them from apologizing for their behaviors, mostly because of the fear they experience (Alcoholics Anonymous, 2010).

The current study is concerned with three dimensions of forgiveness in the context of Alcoholics Anonymous. Despite the literature examining the success of A.A., relatively little is known about the internal dynamics of the 12 -Step process that are related to the overall success for participants. Most importantly, research within the realm of A.A. and the forgiveness steps has not yet investigated the process one 
experiences when asking or seeking forgiveness from others, themselves, or God. This study explores this topic in the context of A.A., while adding to the overall literature on forgiveness-seeking experiences and behaviors. Since the steps have been shown to be so crucial in program success, research needs to investigate the amends process and the process of asking for forgiveness in general.

The Worthington and Wade (1999) model of forgiveness has important implications for this research. It details the two reactions a victim can have to an offender (i.e., acceptance or rejection of an alcoholic's amends). It also sheds light on what forgiveness and unforgiveness may look like to an alcoholic during their amends. This foundation will allow the research to explore what the experience of receiving forgiveness and unforgiveness is like for the alcoholic, and its effect on sobriety. Unforgiveness will not be explored in the data analysis of this paper, as it describes an emotion that someone other than the alcoholic would feel, and any discussion of it in context of the theory would be based on the view of the victim. This study will investigate the relationship of forgiveness of the alcoholics themselves, their Higher Power, and the other person during the process of making amends, as well as its effect on their sobriety. 


\section{CHAPTER 3}

\section{METHODOLOGY}

\section{Study Aims}

This study addresses the gap in the literature by focusing specifically on the issues surrounding the concept of forgiveness, and how it is defined, experienced, and integrated into the participant's involvement in the 12 Step program of A.A. The utilization of a qualitative design is especially useful in the early stages of research, when little information is available on the topic and there is a need for basic understanding of those issues related to the "who, what and where" questions (Sandelowski, 2000).

\section{Methodology}

A qualitative design using semi-structured interviews was used for this study, as a basic description of the process, significance, and meaning of forgiveness was investigated. The questions were piloted with two alcoholics before data collection to ensure questions were appropriate and clear for the purposes of this study. Both pilot studies confirmed that questions were accurate and asked the desired information.

\section{Participant inclusion criteria.}

In-depth interviews, ranging between 29 and 48 minutes in length, were conducted with six alcoholics, three women and three men, currently in the Alcoholics Anonymous program in the Fairfield County area of Connecticut. Five of the six participants had between 15 and 25 years of sobriety, and only one participant had 6 
years. The number of participants was consistent with a recent University of Rhode Island's graduate student's qualitative Master's thesis on African students' identity formation, where six students were interviewed (Cole, 2009). Data saturation is the term used to describe when no new codes or themes have emerged from the data, and usually indicates that data sampling is complete (Marshall, 1996). Data saturation was reached by the fourth interview, with the exception of the Higher Power, in terms of the effect of the bad amends. This is will be discussed further in the findings and discussion sections of this study. Participant inclusion criteria were:

1. 18 years of age or older.

2. At least two years of uninterrupted sobriety in the A.A. program, which included refraining from drinking behavior for two uninterrupted years. Two years of sobriety were required, as the stability of participants' sobriety is of utmost importance. It was also thought that participants with a shorter duration of sobriety may also have had fresher memories and experiences than someone at two years, which could have caused them discomfort during the interview.

3. Completion of the 12-step recovery process at least one time during their sobriety. Completion of the 12-step recovery process was defined as having attended Step Meetings, where a step is discussed each week and alcoholics then complete this step with their sponsor. This is important, as this study examines the experiences alcoholics endure during the amends process, which takes place during Steps 4-9. 
4. Having made or attempted at least one amends that was rejected. A rejected amends was defined in two ways: (1) as a situation in which a person listened to the alcoholic's amends, but refused to accept their amends and forgive the alcoholic, and (2) as a situation in which a person refused to meet with the alcoholic so that they could make their amends. This study hoped to compare both successful and unsuccessful amends experiences; however, it may be less likely that alcoholics experience an unsuccessful amends. Therefore, it is necessary to make this part of the inclusion criteria so that experiences can be compared and contrasted.

\section{Recruitment.}

Participants were recruited using a flyer that was handed out by the researcher at an A.A. Step Meeting in Shelton, Connecticut (see flyer in Appendix C). Five participants came from Connecticut, and one from Rhode Island. Snowball sampling was used, as one participant would tell another A.A. member of their participation in the study (Plano Clark \& Creswell, 2010). The flyer gave basic information about the study, including the topic of forgiveness within the amends process, duration of interview, recording devices used, maintenance of participant confidentiality, and researcher contact information. Those alcoholics interested in participating in the study were encouraged to contact the researcher with the given contact information provided on the flyer. Although the researcher took measures to ensure confidentiality of participants, participants did not seem concerned about sharing their participation in the study with their A.A. peers.

\section{Human subjects approval and informed consent.}


Before starting the interview, participants read and reviewed the anonymous consent form approved by the URI Institutional Review Board (IRB) (see a copy in the Appendix D). This consent form included the basic purpose of the study, what would happen during the interview, procedures to insure anonymity of data, discussion of risks and benefits, and contact information for the researcher and faculty sponsor. The anonymous consent form was used due to the importance and tradition of anonymity in the A.A. program.

Four interviews were conducted at a privately reserved library meeting room, one at one of the participant's homes, and one outside the library in a private gazebo. All interviews, except for one, were uninterrupted. The one interruption occurred from a woman knocking on the door to the meeting room, requesting the researcher and participant lower their voices.

\section{Data Analysis}

The researcher used a digital recording device to record interviews with participants. Interviews were transcribed by the researcher and analyzed using Miles and Huberman's (1994) methods for the analysis of qualitative data. Miles and Huberman (1994) suggest that interviews are read through at least once to gain an overall sense of the data. The researcher read the interviews from beginning to end twice, before starting data analysis. During the second read, the researcher began adding marginal notes, which are used to keep in mind the overall sense or ideas of the data. Although Miles and Huberman (1994) suggest doing this after codes have begun to be collected, the researcher felt that due to her inexperience with qualitative data 
analysis, adding marginal notes at the beginning of the process was more beneficial and optimized organization.

Due to the initial reading of the data, the researcher felt it most beneficial for the organization of thoughts and codes to occur if responses were grouped by question. Miles and Huberman (1994) explain that interviews should be organized and analyzed by the use of codes, after preliminary reading have been finished. Codes are tags, labels, or words placed in the margins of the interviews and are assigned to phrases, paragraphs, or sentences of data (Miles \& Huberman, 1994). This study used descriptive codes, which are literal labels used to highlight text segments and are easily discernible simply by the word chosen to represent the code (for examples of descriptor codes, see Appendix E).

During the development of descriptive codes, the researcher added a few steps not specifically laid out by Miles and Huberman (1994), as a way to feel more comfortable with the data analysis process. In these steps, responses were cut and grouped by question, so that each participant's response to each question was assembled in one pile. This helped insure organization. The researcher then read the interviews according to each group's responses and added more marginal notes to develop further familiarity with the data. In addition, key words and phrases were also underlined and served as the preliminary creation of the codes. Interviews were read again in their respective groups to ensure that no key phrases or words were overlooked.

Those key phrases and words that were underlined were now highlighted with different colors to represent the codes for each question. Going question by question, 
the researcher then compiled the codes on a sheet of paper, and looked for discrepancies and redundancies. A discrepancy is a code that does not have a similar meaning compared to the other codes, and seems to suggest a new idea not previously explored in the data (Miles \& Huberman, 1994). Redundancies are two different codes that mean exactly the same thing and can be condensed into one code (Miles \& Huberman, 1994). For each question, the codes were then written on a piece of foam board to insure organization, where the codes for question one were written on one board, and so on. Next, the researcher flipped over the boards to the unwritten side, hung them one next to the other, listened to each interview on iTunes, and wrote down key words and phrases the participants said according to each question. This allowed the researcher to double-check her work done previously, and to see if the key words written on the boards matched the codes found in the first round of coding.

Once all of the interviews were listened to and their key words and phrases written on the boards question by question, the researcher then looked at one question at a time to check for congruencies with the codes found in the first round of coding. Checking for congruencies signifies that there are no discrepancies found among the codes, and that codes illustrate the same general sense for each idea (Miles \& Huberman, 1994). Codes were placed into a codebook organized by question (see an example of a coded interview in Appendix F). From the codebook, the researcher was able to easily read through the codes per question, develop a larger sense of the data, and construct five themes. Themes note the reoccurring patterns in the data that weave together other sections of the data outlined by the codes (Miles \& Huberman, 
1994). They can help tell the story about the overall meaning of the data found in the interviews (Miles \& Huberman, 1994).

Three transcribed interviews were read by another Master's student researcher and coded, using the same themes and codebook developed by the primary researcher. To measure reliability, the two researchers discussed their findings and calculated the number of agreed upon codes, divided by the total number of agreed upon codes and disagreed upon codes (Miles \& Huberman, 1994). This was done to insure that both researchers saw the same patterns and themes emerge from the data (Miles \& Huberman, 1994). Miles and Huberman (1994) stated that a sound reliability score is $70 \%$; the researchers reached a reliability score of $97 \%$. While the researchers agreed on most of the codes, the differences that emerged were discussed. Researchers met and resolved the difference in interpretation surrounding whether the code of fear of rejection was accurately described in the theme fear of responsibility.

The researchers agreed that in order for the participants to have a fear of rejection, they must first have to go through the fear of taking responsibility. The two researchers also agreed to add codes under various themes to ensure that all of the relevant data was represented under themes. This became the focus and purpose of the second coder, as codes that were missed in the first round of coding were brought to the attention of the primary researcher and added under the respective theme. Each time a new code was added to the codebook, the researchers discussed whether that theme was still an accurate descriptor of the codes that were added. Only one theme, freedom from past behaviors, was modified from simply "freedom" to "freedom from past behaviors" to accurately represent the added codes from the second researcher. 


\section{Interview questions.}

The following questions were used in this study. Probes were used as necessary (e.g., What did that feel like? How did that affect you?). All questions were first read to the participants so that they could gain a general idea of how the interview was structured. Questions were then asked one at a time.

1. Tell me about what it is like when you were preparing to make amends. Can you describe the emotions you experienced?

2. When you think about your successful amends, how/in what ways did they affect your relationship with yourself, your Higher Power, and the person accepting your amends?

3. When you think about your unsuccessful amends, how/in what ways did they affect your relationship with yourself, your Higher Power, and the person rejecting your amends?

4. How has making your amends, both successful and unsuccessful, affected your sobriety? Can you give some specific examples?

5. Given your experience with the steps involving amends, what advice can you give about how to prepare someone for these experiences? 


\section{CHAPTER 4}

\section{FINDINGS}

\section{Introduction}

The first part of this chapter re-examines the definition of a bad amends, as the participants in this study defined it. The following section details the themes that developed in this study: (1) fear of responsibility, (2) second chances at healthy relationships, (3) transcending the harm, (4) freedom from past behaviors, and (5) importance of the sponsor. All participants' names have been changed to pseudonyms to protect their anonymity.

\section{Defining a Bad Amends}

In the initial stages of this study, the researcher suggested that alcoholics can have two different outcomes to their amends, which render them successful and unsuccessful. However, when speaking with the A.A. members who participated in this study, the researcher noticed that the terms "good" and "bad" were more commonly used to describe amends. As this was the case, the flyers distributed for this study used the word bad, and defined a bad amends in two distinct ways (see Appendix B for flyer and definitions). Also, the questions used in the study were modified during the interview to use both the words bad and unsuccessful to describe negative amends.

Before beginning the interview, the researcher read through the questions to give participants a sense of the questions that would be asked. When the third question was read, the experience of a bad amends, most of the participants interjected 
that they had never experienced a bad amends. The researcher re-explained the definition provided on the flyer, and participants politely pointed out that they had experienced an amends similar to what the researcher had described, and while the reaction of the other person may have been "bad," their amends was still successful because of their attempt to make it. In light of this, when asking the third question, the researcher asked participants to think back to the time when they still thought of their experience as negative. In order to be consistent, this study will continue to refer to those negative experiences as the bad or rejected amends and the positive experiences as the good or accepted amends, as the participants were asked to think back to that time when the amends was still considered as such.

It is also helpful to note the experiences participants chose to talk about when describing their bad amends, as this leads to an expansion of the definition and a better understanding of the responses participants gave. For example, Lynn's bad amends consisted of a verbal argument she and another woman from the program fell into. Susan had a similar experience, except that after she had explained her part in the harms she had caused, her friend swore at her and walked out of the coffee shop. Richard described the financial amends he tried to make, but his money was rejected and he was escorted out of his previous employer's office. Tom explained that after making an appointment with his mother and driving from Connecticut to Canada, she refused to meet with him. James's bad amends was also financial, because when he could not come up with the lump sum owed on late rental payments, his landlord wished him no harm — only years later to become upset that he was not repaid. Finally, Amy's bad amends was the most interesting and the furthest away from the 
definition used by the researcher and the Big Book. Amy's bad amends was that her brothers did not remember any of the harms she mentioned, and their response was neither positive nor negative, but neutral.

How a bad amends is defined is a subjective definition. Participants viewed the bad amends very differently from each other, but it seems as though a bad amends can be categorized by feelings of dissatisfaction, a lack of validation, or a lack of response. Although there were different definitions of a bad amends, participants generally expressed the same emotions and feelings during the interview process.

\section{Themes}

\section{Fear of responsibility.}

Participants uniformly described the fear of taking responsibility for past harms and behaviors when preparing to make their amends. First, the fear of responsibility was evident when participants were preparing to make their amends. In the $4^{\text {th }}$ Step process, participants go through a rigorous personal inventory in which their destructive behaviors and harms must be admitted to the self and another person, usually the sponsor. This responsibility of the self causes fear for alcoholics since many have to reflect on shameful past behaviors. However, it is through this process that alcoholics are able to face their harms and take responsibility for the past, thus embarking on a life committed to sobriety.

They described the fear in looking at themselves and their role in their shameful behaviors. One participant, Richard, explained, "The-looking at myself was definitely the hardest thing, ya know_ — cause I didn't want_-didn't want to admit and take responsibility for the things I had done." Tom responded, "Cause I had done 
a lot of things... at the time I was ashamed at a lot of things I had done....I was full of fear...” James said, “....the $4^{\text {th }}$ step is scar-it scared me only because I knew I was gonna have to look at myself."

Amy described similar feelings when she said, "So then I had to start from square one and say, okay where's my responsibility—okay, Amy you are responsible for your behaviors...even though...you were altered." Tom described the depth of this responsibility process when he said that alcoholics must first look at, “....what did they do [the other person], what did I—what did it affect in me, what did....I do, what was my part in it and what were my defects that were blaring. Ya know, was I selfish, inconsiderate, self-seeking.....and frightened....did I character assassinate people, did I lie to people...". This describes the degree to which alcoholics must assess their past behaviors, as well as illustrates why this would be a fearful process, since alcoholics may have to admit to shameful behaviors, as Tom described earlier.

Participants also described the fear of having to tell their sponsor the harms they had caused. Susan said, "Because...seeing something in black and white—it's hard to deny. And then knowing that you have to share it with another person, that's huge too." James said, "Ya know, they tell ya, don't worry about the next step and you're like—step 5 is comin up and you're gonna have to-you're gonna have to talk to somebody to do the...to do the confession type thing...". The Big Book notes that the importance of writing harms in black and white prevents the alcoholic from denying their character defects and harms, a central part of staying sober (Alcoholics Anonymous, 2010). The Big Book also states that sharing these harms with another person sheds light on the most shameful parts of an alcoholic's past, but that this 
creates feelings of pride and peace (Alcoholics Anonymous, 2010). However, participants did not discuss their experience or feelings after having shared their harms with their sponsor; they simply noted that this was a daunting task.

\section{Second chances at healthy relationships.}

The second theme characterizes a second chance at healthy relationships for the self, Higher Power, and the person receiving the amends. The accepted amends allowed the alcoholic to feel self-esteem and confidence through their admission of their harms to another person, which in turn created more trust and awareness of the Higher Power, and a healthy relationship with the other person. The relationship building was contingent on the other person's response, and seems to influence the way the alcoholic views the self and Higher Power. Although alcoholics are taught not to focus on the outcome, it is evident that when the outcome is positive-i.e., the amends are accepted - there is a smoother transition for the self and Higher Power, as well as the other person in moving toward healthy relationship-building. In the accepted amends, healthy relationships for the self, Higher Power, and other person are influenced by each other.

In terms of the self, participants noted that they felt increased amounts of selfesteem and confidence. Lynn explains, “...it makes you feel more comfortable and more confident in your day to day stuff." Susan gave examples of her self-esteem developing when she shared, “...I still got a job, and I'm feeling good, and I've got friends... and I haven't killed my cat, I still have my car, I paid my rent.” James stated, “...we don't walk around lookin' at the ground anymore...now I walk down the street and I-I wanna smile at everybody I see, just to see if they smile back....”. 
Tom admitted that, “...it made me want to live longer...I would ask God every night not to let me wake up because I was in such pain.” In essence, the good amends provided the self-esteem needed to develop a new attitude or relationship about the self.

Amy touched on another aspect of self-esteem, which was powered by the sense of freedom to become a different person. She shared, “...I felt more freedom, I felt more serenity, I felt more peace, I felt cleaner, I felt like I could change and grow even further...". Later in the interview she said, "And I forgave myself." Richard echoed this new freedom when he said that the good amends allowed him to "...walk without the weight on my back of all the stuff I did. Because those things will haunt you and cause you to go back to your old behaviors, and then eventually drink and drug again." For these alcoholics, the new relationship that was created for the self was filled with self-esteem and confidence and fostered the freedom to begin anew. A second chance for a relationship with a Higher Power was also formed, even for those who might have had an existing foundation previous to coming into the program, or from Steps 1 through 3. Richard stated that, “...the amends process is constantly building on that [relationship with the Higher Power]." Like Richard, Tom explained, “....well God's always been involved in it for me...I have a different outlook on God today than I did initially in sobriety...I'm a deacon in my church...I'm involved in all kinds of activities...". Lynn discussed her increasing awareness of her Higher Power when she said, "It's the first time that you really getyou get that feeling that someone's arms around you... That's when you start to feel loved, when you start to feel warm and safe." Amy explained that no longer feeling 
shame was in part feeling her Higher Power's love. She said, "God, you love me! You love me no matter what! But I didn't know that I loved myself...before I could let God really show himself to me.” Susan observed that, “...it developed my relationship, I didn't really have one before then.” James added, “...the good amends, they make your spirit soar....". This was an important aspect of the amends process for participants, as developing a relationship with a Higher Power is a central part of A.A.

The relationships with the people the participants were making amends to changed drastically as a result of the amends. Participants shared many specific examples of these close relationships where they felt of value to the other person and vice versa. Lynn explained that her relationship with her father ".....really flowered until he died....We became very close. Before that, I would say we weren't close at all." Richard said that he shares his yearly sobriety coin with his mother, and that “...she cries every year for 15 minutes still, it's just amazing.” Furthermore, Richard stated that he was more of value to his sisters because they no longer have to "...have beer...at the house just to get me to come over for holidays....there's more of a depth to our relationship." Susan mentioned that she and her brother are "...so close now...I didn't think that would ever, ever happen."

Richard, James, and Tom mentioned the spillover effects the good amends had in their work relations. James recalled owing people money while he was actively drinking, but once he got sober he, “...could go shopping for lumber and paint and stuff like that and not have to worry" about running into someone to whom he owed money. Tom mentioned, “...there was less head banging at work....because of the 
amends process, because of sayin' it out loud." The second chance at relationships that developed for participants was key to their self-esteem, the strengthened connection they felt to their Higher Power, and the value they could be to their families.

\section{Transcending the harm.}

Transcending the harm was the third theme, and it embodied very rich data on the process that an alcoholic goes through when they encounter a bad amends. In this process and theme, participants described transcending the harm, in which the self, Higher Power, and other person are all harmed as a result of the bad amends. Here, feelings of shame, remorse, and guilt find their way back to the alcoholic because of the other person's negative reaction. Much in the same sense that the good amends was a positive process toward relationship building, the bad amends may counteract this process.

After harm is done to the relationship with the self and other person, the alcoholic begins to transcend this by reflecting on the experience or talking with their sponsor. The alcoholic realizes that the reaction of the other person is indifferent to the completion of the amends, because the attempt to make the amends is the only thing that matters. Therefore, whether the reaction of the other person is accepting, rejecting, or indifferent has no bearing on the alcoholic, because the successfulness depends on the attempt. Additionally, it is in the transcendence piece that alcoholics learn to "clean their side of the street" only and not feel accountable for the other person. To clean one's side of the street means to for alcoholic to take responsibility for themselves only, regardless of the harm the other person might have caused them 
(Alcoholics Anonymous, 2010). The amends are then realized to be a selfish process, where the most important part is that the alcoholic makes an attempt to clean their side of the street, and understand that they cannot control the outcome.

Participants described the harm done to the self, caused by emotions such as shame and guilt as a result of the reaction they received. Lynn said, “...it brought me back to the remorse I had when I first came in... the pain and the remorse and the selfhatred, and the...I can't do anything right stuff came all back." Amy explained that she was frustrated because her brothers would not give her validation. She remembered feeling frustrated that they, “...can't tell me I'm—I'm not to feel anymore shame?!” Susan noted that “...I felt less than, I felt a hole...”, while James said, “...I felt like something was undone...” and that “...maybe I did something wrong...". Contrary to the relationship-building that occurred in the good amends, participants' relationships experienced damage in the bad amends, through their feelings of remorse and guilt.

When asked about their Higher Power, participants had very mixed responses. Richard shared that, "Even in the midst of my addiction...I was never really like one of those....angry at God type people." James had something similar to say. "I'm all done blaming God for things...I don't think God does things to us, I think-I think free will gets us in a lot of trouble and we blame God...". Tom also explained that his relationship with his Higher Power did not change because, "That was just about me failing. It was all about me failing. It wasn't about God, it wasn't even about my mother not wanting to hear it. I just thought, I must have done something wrong to prompt this." 
Alternatively, Lynn had something very different to say. She explained that her relationship with her Higher Power was harmed because, "I had to go back to step 3. I didn't want any part of the Higher Power stuff cause he didn't — he didn't come through for me. I was angry." Amy experienced similar feelings of rejection with her Higher Power when she said, "I probably didn’t feel worthy...I did something wrong." As she continued, she began to get choked up, but went on to explain that she thought, “...I'm bad, I'm ugly...I couldn't relinquish the shame...I kinda pushed my Higher Power away...I'm not good enough, I'm not clean enough, I'm not whole enough." Susan was the only participant who said, “...I didn't really understand what it was," and that, “...it's not that I don't believe, it's that it's still I think developing." The variation in the relationship effect on the Higher Power will be discussed further in the discussion section.

In the last part of the question, participants talked about the effect of the bad amends on the other person. As the definition of what a bad amends varied for participants, so did the other person's response. For most participants, the relationship and communication ended immediately. Lynn stated, “...I stormed out of the diner and told her I'd never talk to her again." Susan's friend said to her, “ 'I don't accept your amends-your apology'...she didn't want any part of it." Richard had the most dramatic experience, when he explained, “...he just went on a vulgarity...laden...tirade and...called in six guys from the warehouse and escorted me out of the office."

Tom, James, and Amy had different experiences in how the other person reacted, which were subtle, yet still detrimental. For these participants, it seemed that 
even if there was no change in the relationship (i.e. the alcoholic and the other person were not communicating before and that lack of communication continued), the alcoholic was affected by it. Tom explained that when his mom broke their agreement to meet, he remembered saying to her, " 'Yeah, we-well we made this appointment' and she 'I understand that' she says, 'but I don't wanna do it.' " James described the uncomfortable feelings he felt when his past landlord went back on an agreement they had made for back rental payments. “...fast forward a couple years apparently he - he forgot about that. Ya know, he only remembered that I owed him a lot of money...there was this vibe...". Since Amy's brothers did not give her a reaction, she had to assume that they had accepted her amends, but she makes it a point throughout the interview to mention that no one has verbally thanked or accepted her amends. Instead she has learned to infer, “....his pysch, and his energy feels...that it touches him still." Regardless of the difference in situations, all participants felt that some harm had been done to the self, their Higher Power, and the person immediately following the experience.

When participants were asked to talk about their bad amends experience, the researcher had to continuously ask them to return to the moment when it first occurred, rather than their thoughts on the experience today, because participants often described two different meanings of the experience. One was related to the harm felt directly following the experience, the second was the transcendence participants came away with after some time. During the interview, participants would talk about both simultaneously, noting that where they once felt harm about the self, their Higher Power, and the other person, they now understood the experience in a different light, 
that it no longer could be described as harm. This response is described as the transcendence over the harm.

In the transcendence part of the theme, participants described understanding that the reaction of the other person was not an outcome they could control, that their attempt was the only part that mattered, and that they were responsible for cleaning their side of the street only. In A.A., this colloquialism describes the alcoholic taking responsibility only for themselves, rather than focusing on how others may have hurt them. In this way, the focus of the amends is for the alcoholic only, and any harm the other person reacts to or feels should not prevent the alcoholic from feeling that their amends is complete. As Tom explained, “...the book says, that we make an attempt to clear it up. Whether we're successful at them accepting it, or hearing it, is not up to us. Our making the attempt is the success part." Amy stated, "I just had to believe and trust that it makes a difference. And if it didn't make a difference to me...then it didn't make sense to do it." Susan shared that after her bad amends, she told her group, “You said this was supposed to go really, really well and it didn't!...but it did....because I learned from it....the amends wasn't...for her and it wasn't necessarily for her to say everything is nice-nice it was for me to take responsibility for what I did....I wasn't in control over her reaction and the outcome...". For James, it was “.... lesson learned... it seems like I've learned something and I’ve grown...it—it worked out...”. Similar to James, Lynn also felt as though she was learning a lesson through her Higher Power when she said, “...they're lessons...exercises in getting closer to - to God. Loving yourself, which is the same thing as loving God, is what I found out." In this way, the guilt, remorse, and shame 
felt by the self as a result of the other person not accepting their amends is seen as irrelevant to the completion of the amends. As participants explained, the act or attempt of making the amends denotes the successfulness and completion, not the reaction of the other person. Thus, there is no need to do harm toward the self through emotions such as guilt and shame, when the act of making amends itself justifies their execution of the step.

\section{Freedom from past behaviors.}

The fourth theme captured the freedom participants felt in completing their amends. This freedom is connected to their sobriety, in that participants felt that admitting to their past behaviors allowed them to begin a new life that moved away from their character defects and required abstinence. To participants, the duration of time in which an alcoholic abstains from alcohol is somewhat insignificant if they are not incorporating the 12-Steps into their daily lives. In this theme, the quality of sobriety seemed extremely important to participants. Furthermore, this theme also described the amends as a life-long process. Rather than an isolated event, this process must occur constantly, because what is important is not only that the alcoholic does not drink, but that they discontinue the destructive behaviors that were intertwined with their drinking.

This idea that involvement in A.A. is more than abstaining from alcohol and going to meetings was also illustrated by participants' views that they did not want to be the "dry drunk," that they wanted to grow as a person, change their lives, and take part in a spiritual journey. In fact, much of the focus of the interviews was not on how long participants had been abstinent, but rather on how much they had changed their 
lives. Participants made the choice not only to stop drinking, but also to change their behaviors, which was seen as a crucial step in the quality of their sobriety. The freedom the amends process gave participants allowed them to embark on their new spiritual journey, and illustrates some of the most important and telling information about the dual purpose of the A.A. program.

Richard very plainly explained the purpose and critical nature of the amends process when he said it allowed him "...to live free now...we do this, so you can walk...without fear...resentment...that's what serenity is...". Highlighting the importance of the amends, he said, “...if you don't...recognize your character defects....and figuring out your resentments, fears, and harms — and if you don't fix those then you're gonna drink again almost right away." For Lynn, the amends "has been the one thing that has solidified my relationship with my Higher Power. Serenity to me means, everything's gonna be okay. It's because I have... relied on something other than myself. A Higher Power." She also explained that, “...we do whatever we need to do initially, and then we have to change our way of life....they're [making amends] so relieving. Today, I'm having healthy relationships... as a result of making this other amends...". James said that his sobriety was “....definitely stronger," since having done the amends. He went on to explain that he received DWI charges and made his amends by taking the mandatory classes. Now that he is sober, when police cars drive behind him he said, “...I would look in the mirror and I...wish you would pull me over...they can't anymore...cause I'm not doin' anything wrong now. Ya know, and what a great feeling that is...". Susan shared that the amends have helped her, “...understand my role in the harms done um to someone...not feel sorry for 
myself and...grow....You gotta do the work...I'm grateful...I have a lot of blessings." She also mentioned, “...people could come to A.A. and not drink and go to meetings...or...they could change everything about their lives...”. Amy's statement echoed this belief when she stated, "I didn't want to have that same emotions and feelings that I felt when I was drinking and drugging...cause it was like, hey I might as well go back to using...I-I-I didn't get into recovery so I could just be abstinent. I got into recovery because I wanted to grow beyond. So that I wouldn't be the dry drunk...". Tom said, "It's freed me, from, ya know, worryin' about the things in my past, it's freed me from living in the past...I occasionally look back to make sure that, ya know, I'm not repeating those old behaviors...".

In this theme, participants describe the purpose of making amends not as a one-time act, but as a beginning of a new life, where past behaviors are left behind and new ones take their place. For the alcoholic, making amends begins with admitting to certain character defects and becoming aware of the harm they have caused others. In making amends, the alcoholic makes a conscious effort to no longer practice those defects, but to correct them and engage in positive behaviors. The amends process is an outline for a new way of living, and also describes Step 10. Tom said, “...I do a 10 Step and...recognize that I hurt somebody and I—right away I go make the amends.” Amy also talked about Step 10 as a habitual amends process. “...every morning...I'm ready to take my amends. Ya know, today, I promptly admit it...I'm so vigilant." Susan shared that making amends has changed her from, “...instead of being... selfcentered and...egocentric...someone said...'You're one of the most empathetic people I've ever met.' " Lynn shared this thought when she explained that after her 
bad amends with a fellow member, “...when I hear her talk, I am so empathetic...But you can see what I had to go through to get there."

\section{Importance of the sponsor.}

Lastly, the importance of the sponsor was an unanticipated, yet very important, theme participants described. Many participants named specific instructions that alcoholics need to follow in the amends process, but many of these instructions were tied to the sponsor. For example, in making the appointment, an alcoholic must first have a second opinion of which amends are appropriate. Linked to this is another piece of advice participants gave, which was to never make an amends where it would cause the other person harm. There again, the utilization of a sponsor is needed to determine if an amends, or a detail about that amends, will cause further harm. Also, participants advised that alcoholics be sure they are ready and willing to make an amends, another example where the sponsor aids the alcoholic in understanding when the timing is right for both the alcoholic and the other person in making that amends.

Many participants felt that a sponsor was crucial to becoming successful in the program, and much of the advice given for this question was shared when participants talked about their own experiences with making amends. Lynn spoke about the intricacies of the amends process instructions, but first noted that the most important thing to keep in mind was that, "...we're not in the outcome business. The way these go is the way God intends them to go...”. She also said, “....if we're working with a sponsor, we're not likely to make mistakes...” Lynn also stressed, “...you need an appointment..." and that this allows the other person the opportunity to say 'no', which helps the alcoholic become, “....altruistic...you need a sponsor to help you do 
that...". When making an amends, Lynn thought it was very important that a person, “...write down on a card what you're going to say, and go over it with your sponsor...So the preparation on these is important, always with a sponsor, never on your own."

Tom shared other advice, such as being cautious when a detail about an amends might cause further harm because, “...we're in this process to not hurt people anymore.” He also mentioned, “...make an appointment...that's changing our behaviors. And not just doing what we want," and “...don't do it by yourself...use a sponsor...You do it by yourself...you're gonna run into quite some problems." Susan elaborated on why a sponsor was key advice, explaining that, “....I had many more people on my list than it was appropriate for me to make amends to so it took someone who was clear thinking and maybe objective...just to help guide through the process." Like Lynn, she also added that, “...you're taking responsibility for yourself and-and you have no control over the outcome...”. Richard shared, “...make an appointment...discuss...every one with your sponsor...not always your perspective on the situation is correct." He also stated that, “...you can't make everybody happy...you can't take responsibility for their anger... as long as you're willing...your job is really done with that amends...". Amy added that alcoholics should "...evaluate what they needed to get out of it," and to remember that the amends is, "...to know that you did the best you could." Like the other participants, Amy said, “...I think a good sponsor and a healthy sponsor...is needed... when you're in your own head...you need that objective.” James added, “...take your sponsor and/or your spiritual advisor's advice. No matter how wrong it feels." In terms of gaining another 
perspective, James said, “...you're not always the best judge of whether you're reading or not...Sponsors are very important...you might as well do it right...cause the payoff is huge...".

The importance of the sponsor can also be seen in particular situations where an amends was rejected. Richard described being thrown out of his former boss's office when he tried to make a financial amends for stealing. His boss did not take the money, and so Richard was confused as to whether the amends was complete and wondered if he should return to the office and try to give the money back again. $\mathrm{He}$ called his sponsor, who said, "...you expressed the willingness...They threw you out, the rest is on them, your side of the street is cleaned and you're done." This advice gave Richard the confirmation he was looking for and the ability to feel that he was successful. It also possibly saved him from being thrown out of his former boss's office again, if he had not had a sponsor to prevent him from reattempting the amends.

Tom had a similar experience when his mother refused to keep their appointment. He called his sponsor who told him, "You're done." Once he returned to Connecticut, his sponsor explained to him that the attempt was all that mattered, and Tom was able to put the experience behind him.

In this sense, sponsors are crucial to following the formalities of the amends process, and also as wise advisors during certain situations where the outcome may be unclear to the newly sober alcoholic. Essentially, many of the formalities, if not all, of the amends process cannot be completed without the aid of a sponsor, because they put the alcoholic in danger of harming themselves and others. 


\section{CHAPTER 5}

\section{DISCUSSION}

Five themes emerged in this study, detailing the important aspects of the amends process. Participants first talked about a fear of taking responsibility for their past harms in the beginning of the amends process. Next, they described the second chance at healthy relationships that occurred with the self, the Higher Power, and the other person. Notably, participants described transcending the harm done in the bad amends, and the freedom they felt from the experience in both the good and the bad amends. Lastly, participants described that having a sponsor was one of the most important components for success in continued sobriety. However, the most important finding from this study are the themes of transcending the harm and the importance of the sponsor, because both explain the complexity the bad amends can have for an alcoholic.

The following section will revisit the literature review and discuss the variables related to A.A. success, the variation in the Higher Power found in the theme of transcending the harm, alternative alcoholic self-help groups, dimensions of forgiveness in A.A., the model of unforgiveness and forgiveness within ongoing relationships, study limitations, and future research.

\section{Variables Related to A.A. Success}

\section{Step completion.}


Research (Oakes et al., 2000) has found that working the steps is one of the variables linked to A.A. efficacy. Few studies (Gomes \& Hart, 2009) have measured specific steps and their relationship to A.A. efficacy, and while all 12 Steps are important, some may be stronger indicators than others in their link to sobriety.

This study focused on Steps 4-9 in particular, but did not outwardly ask participants if they believed these steps had a strong influence on their sobriety. Rather, this was an insight the researcher hoped would come through in the interviews. In the first interview, Lynn mentioned that she thought the amends process was critical to the program. She said, “....when you go through this $4,5,6,7,8,9 \ldots$ That's when you start to feel loved...." She went on to say that, "More people relapse over step 9, or lack of, than any other step...It is the program...it solidifies the whole program." The researcher then became interested in the other participants' thoughts on the importance of the amends process, and so the importance of Steps 4-9 was asked in every interview. Tom stated, "Absolutely. Without a doubt. I think if you took that part out of the process, it would not work...I'm convinced of that...if I-I had to say that two are more important than the rest, the $4^{\text {th }}$ and the $9^{\text {th }}$."

Richard responded to this question by saying, “....it's quintessential...But when you don't do 8 and 9 , that past will come back and bite you....You can try to put it off as long as you want, but ya have to be able to move on after doing the amends...". Amy explained, "Yes...relinquish your own inner turmoil...if you don’t grow past that behavior...it's not as growing as a process...Ya know because you picked up over those things... you picked up over your shame...”. Susan shared, “...I 
would agree with that...I think it's probably one of the most critical parts of staying sober, but you can't get to 9 unless you do the rest before it."

The link between the amends steps and sobriety was highlighted in participants' responses to this question, as it was in the fourth theme of freedom, because participants focused more on the behavior change than the number of days or years the amends steps allowed them to stay abstinent. Although abstinence is the ultimate goal, for members maintaining sobriety is possible in part because of this amends process. The behavior change that occurs as a result of doing the personal inventory and making amends outlines the new behaviors members will strive to practice in their recovery process.

\section{Helping in A.A.}

Previous research has established that helping others in 12-Step programs is correlated to sustained sobriety. Engagement in A.A. activities increases self-efficacy, which also contributes to consistent abstinence (Majer et al., 2011; Pagano et al., 2000). Helping others in A.A. was not found to be a common thread among participants in this study. However, when talking about the advice participants would give another alcoholic who experienced a bad amends, most explained that they would share their experiences as a guide for learning. Also, three participants were currently sponsors and named some of the ways they helped their sponsees, but explicit helping in A.A. as a variable linked to success could not be determined.

\section{Sponsorship.}

The importance of the sponsor was an unexpected theme found in this study, as participants explained that sponsors aid an alcoholic in the many formalities involved 
in completing the amends process successfully. Studies have shown that being a sponsor or having a sponsor is linked to A.A. efficacy (Kaskutas et al., 2003; Oakes et al., 2000) and prolonged sobriety, as well as the probability of staying sober (Tonigan \& Rice, 2010). This study supports these findings, and also adds to the literature on the specific way in which a sponsor is useful. Based on the findings in this study, sponsors can prevent an alcoholic from making amends that may cause the other person, themselves, and their sobriety harm. Additionally, they can confirm the successfulness of an amends, even when it is first categorized as a bad amends, through reiterating and reminding the alcoholic that their attempt is the most important indicator of success in amends completion, not the other person's reaction.

\section{Perceived success in A.A.}

Many of the current variables used to define A.A. efficacy mentioned in the literature review portion of this study are characterized as quantitative. While the quality of sobriety was not highlighted in this study as a key component for success, sobriety quality emerged quite strongly during data analysis. Gabhainn (2003) discovered that quality of sobriety was an important factor reported by A.A. members as a means to success. Participants described quality as being sober, honest, and willing to learn, as well as being at peace with oneself and achieving serenity (Gabhainn, 2003).

These descriptors come very close to describing the fourth theme found in this study, freedom from past behaviors. From both of these studies, it is obvious that sobriety in A.A. is more than going to meetings and not drinking. Rather, it is the 
quality of one's sobriety and that person's relationship with themselves in living this process.

Serenity was also a common term participants in this study used to describe how the good and bad amends affected their sobriety, and many also talked about the necessity of being honest in taking a personal inventory. In fact, being honest with oneself and their sponsor is also connected to the first theme of fear of taking responsibility found in this study. As participants began their personal inventory, they realized that the daunting task of taking responsibility would come only if they were honest, a characteristic that participants both in this study and in Gabhainn (2003) found to be related to sobriety.

\section{Variation in the Higher Power}

There was great variation in participants' responses concerning the effect that their bad amends had on the relationship to the Higher Power. This was mainly due to two reasons: the circumstance in which the rejected amends occurred, and the personal view of the Higher Power. In A.A., participants are allowed the freedom to choose their Higher Power, assuming that whatever they choose, it will be a being of infinite wisdom (Alcoholics Anonymous, 2010). Participants may then be influenced by their own religion or lack thereof, a factor that may greatly determine the change in their relationship with their Higher Power when amends are rejected. One of the central aims of this study was to investigate the relationship between an alcoholic and their the Higher Power, so the variation in this concept speaks to the diversity with which it can be constructed and its affect on an alcoholic. 
Richard and James felt that their relationship with their Higher Power was unchanged because their rejected amends was not of their Higher Power's doing. They also shared that they had some connection to the Catholic faith and both men mentioned the concept of free will, rather than a Higher Power, as something that determines the outcome of a situation. James was advised by his sponsor and spiritual advisor, a priest, that it was not appropriate to make an amends to his landlord. James did not heed their advice, and when the amends was rejected, he did not feel as though his Higher Power was involved in any way. In this situation, the relationship with the Higher Power was unaffected, because of the personal concept of the Higher Power and the context of the rejected amends.

Lynn and Amy shared that they felt anger toward their Higher Power, because they felt abandoned by the rejection of their amends. Lynn shared that she followed the protocol, and “... with a Higher Power's help, I managed to pray for her...I must have prayed for this woman for two years...I wasn't feeling God's presence...". However, Lynn convinced her sponsor that she was ready to make this amends, because she was, “... anxious to get rid of it." After Lynn and this woman argued, and Lynn stormed out of the diner, Lynn explained that she felt angry with her Higher Power, possibly because she had followed the steps and prayed, but her amends was rejected and challenged by the other woman's argument.

Amy shared the same feelings of anger when her brothers showed no response to her amends. Again, the context of the amends is important, because while Lynn's rejected amends erupted into an argument, Amy's was essentially a lack of response. 
However, both women felt abandoned and angry that their Higher Power did not prevent the rejected amends.

Tom expressed that the rejected amends was due to his failure alone, and his mother and his Higher Power were not involved in his guilty feelings. Tom also shared that he was brought up Catholic, but it is uncertain the extent to which this influenced his feelings about his Higher Power in terms of his rejected amends.

Lastly, Susan shared that her relationship with her Higher Power was still developing and so it did not change as a result of the rejected amends. Also, Susan felt that her Higher Power spoke to her through other A.A. members in the meetings, and so it would be difficult to feel a change in the relationship if one believes that their Higher Power speaks through others giving advice. Susan also mentioned, “...I'm Jewish, I'm not Catholic and this is a primarily very seemingly Catholic-based program...". It is possible that this is why Susan's concept of a Higher Power was still developing at this point, and why she did not commit to one form of a Higher Power. Despite the influence of religion A.A. seemed to have in Susan's opinion, she added, “...I can use it to fuel my denial and say, 'I don't belong in A.A.', but I've found nothing....that has helped me the way this has."

The literature also describes a spiritual awakening as a variable related to A.A. program success, where the alcoholic turns their will and life over to their Higher Power (Kaskutas, et al., 2003). This is generally done in Steps 2 and 3, but participants in this study discussed the need to build on this relationship during the amends process. In Step 6 and 7, participants must continue the relationship with their Higher Power that was formed previously, so that they may feel as though their 
character defects have been removed. The concept of a spiritual awakening was not explored in this study, but it seems that all participants had a belief in the existence of a Higher Power.

Although this study investigated the effect both accepted and rejected amends had on alcoholics, a more in-depth and focused study should investigate the development of a Higher Power for A.A. members, as this is a complex process that can strongly influence other components of the program. Much of this formation and influence cannot be deeply investigated in this paper, due to the lack of data on how the Higher Power was created. However, it can be said that a link does exist between the context of a rejected amends and the relationship to the Higher Power.

\section{Alternative Alcoholic Self-help Groups}

The most common criticism of A.A. is the program's idea that a belief in a Higher Power is necessary in order to achieve sobriety (Alcoholics Anonymous, 2010). Groups such as SMART, WFS, and SOS counteract this requirement by either making the use of a Higher Power optional, or doing away with it completely in order to reach those alcoholics who are uncomfortable with the idea of a Higher Power (McCrady et al., 2003). In this study, participants saw the utilization of a Higher Power as helpful and necessary, as it removed their character defects and allowed them to move on in their recovery process.

Contrary to A.A., SMART also allows alcoholics to create their own plan for recovery (McCrady et al., 2003), thus doing away with any type of strict steps. However, the participants in this study felt as though the amends process rules and 
formalities were its most important aspects, so much so that neglecting those regulations would inhibit A.A. program success, i.e., sobriety.

In fact, participants explained that not following the regulations set by the process was the precursor to their bad amends experience. Some participants mentioned that if they had only followed the process correctly, e.g., listened to their sponsor about which amends were appropriate to make, this would have saved them the trouble of causing themselves, Higher Power, and the other person harm. As mentioned previously in this thesis, describing one's harms to the sponsor is a central part of this process for that very reason, and a crucial guideline to follow.

SMART, WFS, and SOS members also feel that the religiousness of A.A. is problematic and a hindrance for membership (Atkins \& Hawdon, 2007). Only one participant in this study remarked about the religiousness of the A.A. program, saying that it seemed largely Catholic-based. However, this still allowed her to form a connection with a Higher Power, even if that relationship was continuously forming.

\section{Dimensions of Forgiveness in A.A.}

This study investigated the three dimensions of forgiveness that occur for alcoholics during the amends process. However, participants mentioned the concept of forgiveness very little; in fact the word "forgive" or "forgave" was mentioned only a total of 10 times across all participants. From the data, it is difficult to conclusively say how much influence forgiveness of the self, the Higher Power, and the other person has on the amends process. The word forgiveness may not properly illustrate what is occurring, as in asking for forgiveness one can be rejected regardless of the attempt, a concept that is reinforced in A.A. as the measure for successfulness. 
However, participants shared that their amends positively impacted their sobriety because of the new behaviors that were created, which allowed them to stay sober. Again, it is difficult to say whether these participants felt as though forgiveness was part of the amends process, due to the reciprocal nature of forgiveness, but this association is possible as research suggests (Webb et al., 2006). Given the data found in this study, it is possible that forgiveness is important for the self and Higher Power, but is modified when making amends to another person. This is discussed further in the following section.

\section{Model of Unforgiveness and Forgiveness Within Ongoing Relationships}

In the beginning phases of this study, it was thought that forgiveness was central to the amends process, due to the researcher's belief that in making amends, the alcoholic is in some way reconciling with the self, the Higher Power, and the other person. During data analysis, it became clear that this was not the intent of making amends. Although it seemed that for alcoholics taking a personal inventory, making an appointment with the person they had harmed, and describing those harms was a reconciliatory act, participants explained that completing these requirements was a healing process for the alcoholic exclusively. As the people alcoholics make amends to can have many different reactions ( e.g., anger, rejection, appreciation, and acceptance) alcoholics learn that they cannot depend on the other person to determine the successfulness of their amends. As was discussed in the findings section, the alcoholic understands that their attempt at making amends is the only determinant of their success. 
Wade and Worthington's (1999) model will now be examined more comprehensively in terms of difference between making amends and forgiveness. In their model, they propose that forgiveness is an internal process, in which one makes a decision to move toward either reconciliation or unforgiveness, with the emphasis on the relationship between the two people. However, this is not the motive for the alcoholic. As mentioned before, the alcoholic is taught that the outcome cannot be controlled, and the point of the amends is to make an attempt to take responsibility and clean their side of the street. Rebuilding the relationship is seen as an added benefit, but not a goal, for the alcoholic.

Alcoholics can receive two different reactions to their amends, as Wade and Worthington (1999) discussed, when the victim can choose to move toward forgiveness or unforgiveness. The alcoholic can also have two different reactions to the outcome, which was illustrated in the ways in which their relationship with the self, the Higher Power, and the other person was affected - the same as the Wade and Worthington (1999) model described for offenders. The new insight that participants added to this model was illustrated specifically in the bad amends. Where they once focused on the other person's negative reaction to their amends, which influenced the way they thought about themselves, their Higher Power, and the other person, they now understood that the reaction was irrelevant and should not affect the relationship with the self, the Higher Power, and the other person. Therefore, as long the alcoholic is willing to make an attempt and does not cause further harm, they should not feel negative emotions. 
Furthermore, the Wade and Worthington (1999) model also suggests that in forgiveness, the offender expresses a willingness to sacrifice for the relationship between themselves and the other person in their attempt to ask for forgiveness. Again, this model is difficult to apply to alcoholics in their $9^{\text {th }}$ Step as the emphasis is on the alcoholic, rather than on the relationship with the other person.

\section{Limitations and Future Research}

This final section discusses the limitations of this study, as well as the implications for future research.

Five of the participants in this study had over 15 years of sobriety and therefore had time to reflect on their experiences, which might explain why they were able to transcend the harm when talking about their bad amends. It is possible that answers might have been very different, and the themes as well, if the memories of their bad amends were still fresh. Also, the data in this study was self-reported and retrospective, so the accuracy of participants' memories of their experiences cannot be guaranteed. Finally, the findings in this study represent alcoholics for whom A.A. has been successful, which may make their generalizability low to others who may have dropped out of the program.

In addition, this study recruited a total of six participants, five of whom were from the Fairfield County area of Connecticut and one from Rhode Island. The participants from Connecticut attended many of the same A.A. meetings, rendering the sample relatively homogenous, and therefore, making it difficult to generalize the findings to other A.A. members. 
Despite the limitations reported in this study, there are important findings presented that future research should explore. First, the way in which an alcoholic creates their idea of a Higher Power can have great implications for how a good or bad amends influences this relationship, as was described in the discussion on the variation the bad amends had on the participants' relationship with their Higher Power. Future research should explore if or in what ways the influences of religion shape an alcoholic's view of the forgiveness they feel from their Higher Power.

Second, future research should investigate and clarify whether forgiveness is a part of the amends process; and if so, to what degree and for whom. Research is also needed to understand how alcoholics define forgiveness, as well as how it is similar to or different from that for non-alcoholics.

Third, future research should broaden or redefine the variables that are used to measure A.A. program efficacy, as the results in this study implied that it has much to do with the quality of sobriety. Related to this, future research should also seek to understand the importance of the behavior change alcoholics commit to when completing their amends and its implications on sobriety and program efficacy.

As shown by the findings in this study, Steps 4-9 of the A.A. program are a very important part of sustaining sobriety. Most importantly, these steps help set the stage for the quality of sobriety, which was seen of equal importance as the amount of time an alcoholic sustained from alcohol. In light of this, future research should not only expand on the variables that measure program success, but also investigate which steps are the crucial links to sobriety. 


\section{APPENDICES}

Appendix A: 12-Steps of Alcoholics Anonymous

Appendix B: Personal Inventory Worksheets

Appendix C: Participant Recruitment Flyer

Appendix D: Anonymous Informed Consent Form

Appendix E: Descriptor Codes

Appendix F: Excerpt of Coded Interview 


\section{Appendix A: 12 Steps of Alcoholics Anonymous}

1. We admitted we were powerless over alcohol - that our lives had become unmanageable.

2. Came to believe that a Power greater than ourselves could restore us to sanity.

3. Made a decision to turn our will and our lives over to the care of God as we understood Him.

4. Made a searching and fearless moral inventory of ourselves.

5. Admitted to God, to ourselves, and to another human being the exact nature of our wrongs.

6. Were entirely ready to have God remove all these defects of character.

7. Humbly asked Him to remove our shortcomings.

8. Made a list of all persons we had harmed, and became willing to make amends to them all.

9. Made direct amends to such people wherever possible, except when to do so would injure them or others.

10. Continued to take personal inventory and when we were wrong promptly admitted it.

11. Sought through prayer and meditation to improve our conscious contact with God as we understood Him, praying only for knowledge of His will for us and the power to carry that out.

12. Having had a spiritual awakening as the result of these steps, we tried to carry this message to alcoholics, and to practice these principles in all our affairs (Alcoholics Anonymous, 2010, p. 59). 
Appendix B: Personal Inventory Worksheets

(Shelton, CT Step Meeting Group, 2011)

\begin{tabular}{|c|c|}
\hline & FOURTH STEP - REVIEW OF RESENTMENTS \\
\hline Column 1 & $\begin{array}{l}\text { I am resentful at: } \\
\text { I list People, Institutions or Principles with whom I am angry }\end{array}$ \\
\hline Column 2 & $\begin{array}{l}\text { The Cause: } \\
\text { I ask myself. "Why I am angry?" What did they do to cause my anger?" }\end{array}$ \\
\hline Column 3 & $\begin{array}{l}\text { Affects My: } \\
\text { On my resentment list, I set opposite each name, my injuries. What was } \\
\text { Injured? Was it My Self-Esteem - Pride - feeling better than someone } \\
\text { else Ego - how you feel about yourself My Security - } \\
\text { Financial, Emotional, or Physical My Ambitions - Plans to gain } \\
\text { acceptance, recognition or power My Personal Relations and/or Sex } \\
\text { Relations }\end{array}$ \\
\hline Column 4 & $\begin{array}{l}\text { What Did I Do? } \\
\text { Putting out of my mind what others have done, I resolutely look for my } \\
\text { own mistakes. What did I do, if anything, to set into motion the trains of } \\
\text { circumstances in motion which in turn caused people or institutions to } \\
\text { hurt me and eventually led to my resentment of them for doing so? Two } \\
\text { Parts: What did I do to start this? What have I done since? How did I } \\
\text { feel? What did I think? How did I respond? How did I behave? Harbor } \\
\text { - hung onto it Allowed it to happen Victim - felt or acted like a victim } \\
\text { Expectations Walls - Do I put up walls? } \\
\text { Irresponsible or I'll show you (retaliation) Lying (Did I lie about it/or } \\
\text { omit it? Self-delusion or deceit Lacking Prayer?/Did I give it to God? } \\
\text { Character Assassination - Physical, mental, verbal, emotional abuse } \\
\text { Drank/Drugged Didn't ask for help Didn't work my program } \\
\text { Isolated/Judged/Overcompensated/ Projected }\end{array}$ \\
\hline Column 5 & $\begin{array}{l}\text { Where had I Been - Which of the above character defects caused me to } \\
\text { hold on to the old resentment, even though I may have done nothing to } \\
\text { cause it? And why?... so I understand These } 5 \text { cover all my defects - } \\
\text { equal to the lowest common denominator. Selfish - without regard for } \\
\text { others would be the thought process (It's all about me) - self- } \\
\text { centered/self-pity Dishonest - lying by omission, self-delusion or deceit } \\
\text { (if you lied in col. 4) Self-Seeking - acted on it/taking action to get what } \\
\text { I want without regard for others Frightened - terror, fear of losing } \\
\text { something I have or of not getting something I want. Fear is chief } \\
\text { activator of all my defects Inconsiderate - Controlling, playing God, } \\
\text { Imposing my will on someone, justifying, manipulating, retaliating }\end{array}$ \\
\hline
\end{tabular}




\begin{tabular}{|c|l|}
\hline & \multicolumn{1}{|c|}{ FOURTH STEP - REVIEW OF FEARS } \\
\hline Column 1 & $\begin{array}{l}\text { Who/What Do I Fear: } \\
\text { I list people, institutions or principles that I fear }\end{array}$ \\
\hline Column 2 & $\begin{array}{l}\text { The Cause: } \\
\text { What are they doing to me? Am I perhaps going to jail? Am I going } \\
\text { to lose something of material value? Am I going to lose face? Will it } \\
\text { result in divorce? Will it destroy a personal relationship? Might I } \\
\text { lose my job, etc? }\end{array}$ \\
\hline Column 3 & $\begin{array}{l}\text { Affects My: } \\
\text { I set opposite each part of self which is affected. Was it my Self- } \\
\text { Esteem, My Security (Financial, Emotional, or Physical), My } \\
\text { Ambitions, My Personal Relations and/or Sex Relations, or My } \\
\text { Pride? }\end{array}$ \\
\hline Column 4 & $\begin{array}{l}\text { What Did I Do? } \\
\text { What did I do, if anything, to set the ball rolling and set the trains of } \\
\text { circumstances in motion which have led to my being in a position to } \\
\text { have the fear? } \\
\text { Harbor } \\
\text { Allow } \\
\text { Victim Playing } \\
\text { Expectations } \\
\text { Walls (Do I put up?) } \\
\text { Irresponsible } \\
\text { Lying (Did I lie about it/or omit it? } \\
\text { Lacking Prayer? } \\
\text { Character Assassination } \\
\text { Drank/Drugged }\end{array}$ \\
\hline Column 5 & $\begin{array}{l}\text { Where had I Been } \\
\text { Selfish, Dishonest, Self-Seeking, Frightened, Inconsiderate }\end{array}$ \\
$\begin{array}{l}\text { Which of the above character defects caused me to hold on to the old } \\
\text { fear, even if I have done nothing to cause it? }\end{array}$ \\
\hline
\end{tabular}




\begin{tabular}{|l|l|}
\hline & FOURTH STEP - REVIEW OF OUR OWN SEX CONDUCT \\
\hline Column 1 & Whom had we hurt? \\
\hline Column 2 & $\begin{array}{l}\text { We reviewed our own conduct over the years past. How had we } \\
\text { been selfish, dishonest or inconsiderate? }\end{array}$ \\
\hline Column 3 & $\begin{array}{l}\text { Caused by: } \\
\text { Which part of Self caused me to do what I did? Was it caused by: } \\
\text { - Social Instinct }\end{array}$ \\
\hline Column 4 $\quad$ Security Instinct \\
\hline Column 5 & $\begin{array}{l}\text { 1. Dex Instinct } \\
\text { Where had I been - } \\
\text { Which of these character defects caused me to do harm to others? } \\
\text { Selfish - without regard for others would be the thought process (It's all } \\
\text { about me) - self-centered/self-pity } \\
\text { Dishonest - lying by omission, self-delusion or deceit (if you lied in } \\
\text { col. 4) } \\
\text { Self-Seeking - acted on it/taking action to get what I want without } \\
\text { regard for others } \\
\text { Frightened - terror, fear of losing something I have or of not getting } \\
\text { something I want. Fear is chief activator of all my defects } \\
\text { Inconsiderate - Controlling, playing God, Imposing my will on } \\
\text { someone, justifying, manipulating, retaliating }\end{array}$ \\
\hline
\end{tabular}


Appendix C: Participant Recruitment Flyer

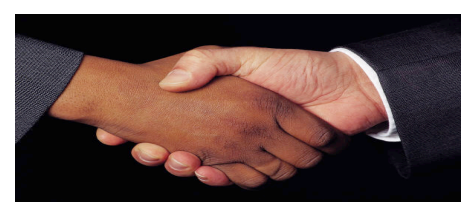

\section{Have you completed your amends?}

Are you at least 18 years of age or older?

An alcoholic with at least 2 years of uninterrupted sobriety?

(no drinking or drugging)

Have you completed all 12 steps at least once with your sponsor?

Then you are eligible to participate in a study about:

Your amends experience: both good and bad. A bad amends is:

- One that was rejected after the alcoholic has already made it (ex. A father meeting his daughter at a coffee shop, making amends to her, but the daughter rejects the father and his amends).

- One where the person the alcoholic seeks to make amends to refuses to meet (ex. A father calling and asking his daughter if he can make amends to her, but she refuses to meet)

How: Allison S. will interview you for about an hour about your experience. Interviews will be recorded and transcribed so Allison can identify the significance alcoholics come away with when they experience a bad amends

When: Interviews will take place in late December/mid January

Where: Coffee shop, or a privately reserved library room 
Your name will not be associated with your interview for the final writing of this study. Your interview is confidential.

If you are interested in participating, please contact Allison S. by phone at 203-414-4451 or email at allisonkgarris@gmail.com 
Appendix D: Anonymous Informed Consent Form

Informed Consent: Anonymous Research

The University of Rhode Island

Department of: Human Development and Family Studies

Address: 2 Lower College Road, Kingston RI 02882

Title of Project: "The Experience of Seeking Amends in the 12-Step Recovery

Process: A Qualitative Study of the Relationship of Forgiveness and Sobriety"

\section{TEAR OFF AND KEEP THIS FORM FOR YOURSELF}

Dear Participant

You have been invited to take part in the research project described below. If you have any questions, please feel free to call Allison S. at (203) 414-4451 or Dr.

Phillip Clark at (401) 874-2689.

The purpose of this study is to understand the experiences and emotions alcoholics face during the amends process in the Alcoholics Anonymous (A.A.) program.

YOU MUST BE AT LEAST 18 YEARS OLD to be in this research project.

If you decide to take part in this study, your participation will involve being interviewed about your experience during the amends process for approximately one hour. The interview will occur either at a local coffee shop or private place acceptable to you. The interview will be audiotaped and later transcribed into a written from.

The possible risks or discomforts of the study are minimal, although you may feel some embarrassment answering questions about private matters related to your amends experience, you do not have to answer any questions during the interview that you choose not to. If these questions are upsetting and you want to talk, please use the phone numbers below: Please contact the A.A. Answering Service to speak to a recovered alcoholic in the Bridgeport, Easton, Fairfield, Monroe, Stratford, Trumbull, Weston and Wesport area at (203) 855-0075 should you feel you need support.

Although there are no direct benefits of the study, your answers may allow deeper reflection on your own experiences within the 12 steps of recovery. The study may also help inform others about the process of making amends, so that they will be able to work this step more effectively.

Your part in this study is anonymous. That means that your answers to all questions are private. No one else can know if you participated in this study and 
no one else can find out what your answers were. Scientific reports will be based on group data and will not identify you or any individual as being in this project. Audiotapes and transcripts of your interview will be stored in a locked filing cabinet at the office of Dr. Phillp Clark, Quinn Hall, Room 100, Lower College Road, Kingston, RI, and will be destroyed after 5 years.

The decision to participate in this research project is up to you. You do not have to participate and you can refuse to answer any questions.

Participation in this study is not expected to be harmful or injurious to you. However, if this study causes you any injury, you should write or call Allison S. and Dr. Phillip Clark at the University of Rhode Island at (401) 874-2689.

If you have other concerns about this study or if you have questions about your rights as a research participant, you may contact the University of Rhode Island's Vice President for Research, 70 Lower College Road, Suite 2, URI, Kingston, RI, (401) 874-4328.

You are at least 18 years old. You have read the consent form and your questions have been answered to your satisfaction. Your participation in the interview implies your consent to participate in this study.

Thank you, Allison S. 


\section{Appendix E: Descriptor Codes}

1. What was it like when you were preparing to make your amends?

Afraid to look at the self (character defects: frightened, self-seeking, inconsiderate, selfish, dishonest) afraid, terrified, fearful, scared, didn't want to do it, procrastinated, fear of rejection, their role in shameful past behaviors: shame, guilty, refusal to admit, dreading the honesty, Having to share harms with a sponsor: afraid to admit to shameful behavior, afraid to share with another person, shame about sharing

2. How did the good amends affect the relationship with your self, Higher Power, and the person you made the amends to?

- Self: self-esteem, confidence, productivity, value to family, new outlook on life, freedom, serenity, self-forgiveness

- Higher Power: strengthened, more trust and awareness, more developed, clarified

- Person: family members most rewarding, developed close relationships with family (ex-wife, brothers, dad, saying "I love you" to mom, giving mom yearly coin), more professional in work relations

3. How did the bad amends affect the relationship with your self, Higher Power, and the person you made the amends to?

- Self: shame, remorse, guilt, failure, uncomfortable, weight, something undone

- Higher Power: felt all accountability for actions, failure was their own, didn't heed advice OR HP was a still developing concept OR abandonment: anger, distance from HP, shame, unworthy

- Person: relationship halted or ended completely, no further verbal communication, caused person harm, avoiding that person

- Transcendence (after some time or after calling their sponsor): Amends for the self, not the other person: responsible for cleaning our side of the street only, Powerlessness over the outcome: attempt is important, not in control of the outcome No such thing as "bad" amends: lessons learned, good experience, deeper relationship: cleaner, stronger, solidified, turning will and life over to HP

4. How have both the good and bad amends affected your sobriety?

Released from past destructive behaviors and able to begin new, positive behaviors, which affect others and HP, cleaned our side of the street, financially responsible, hopeful of the future, New behaviors created, Service to others, grateful, confident, empathetic, humbled, not the same person, Closeness to the HP, new and constant process that allows alcoholic to grow beyond their shameful behaviors by amending the past and practicing new behaviors consistently, Relapse/ineffective program without amends process

5. Given your experience with the steps involving amends, what advice would you give someone who was about to go through these experiences?

Importance of the sponsor: support, prevent bad amends, confirms amend completion when necessary, Warn when an amend will cause 
farther harm (ex-girlfriend), deem which/when amends are appropriate to make (when you are willing), In bad amends, confirm that the amend is completed and help the sponsee move on (street is cleaned, made the attempt, willing) importance of following formalities and rules, Clean our side of the street, not in control of the outcome, express the willingness, Sponsor Following the sponsor's advice, Don't do it alone, use your sponsor for guidance and another perspective or you can cause your sobriety and others harm 


\section{Appendix F: Excerpt of Coded Interview}

A: So that's - that's the process - the general process for all...the alcoholics. So what was it like, specifically for you, in that process? Maybe the first or couple of timesL: Okay, yes, I forgot that you asked that.

A: ...times that you've done it.

L: \{There's a lot of fear...the first time you make it - at least there was for meum... it brings up a lot of fear of rejection, fear of the unknown- $\underline{\boldsymbol{F E} \boldsymbol{A} \boldsymbol{R}}$ \}

A: Mhm.

L: ... ffear of just not being accepted and not knowing, you know, what it's gonna be like, so. $\boldsymbol{F \boldsymbol { E } \boldsymbol { A } \boldsymbol { R } \}}\{$ We go over that a lot, um...in the program where it's worded that, yes we're willing, but we can't be in the outcome business so we're not doing this to get someone's approval. We're simply doing this so we don't drink $\boldsymbol{A M E N D S} \boldsymbol{I S}$ FOR THE SELF, ATTEMPT IS IMPORTANT\}.

A: Mhm.

L: \{Clearing our side of the street. And so um...we have to go into it with that mindset, you know that yes, I'm-I'm scared to death, and yes this could go any way-we don't know how it's gonna go - but we're not in the outcome business. So, we clean our side of the street, we ask them if there's anything they want to say to us and then we leave it at that and we walk away. AMENDS FOR THE SELF, CAN'T CONTROL OUTCOME?

A: Mhm.

L: And so-you know the first one is very scary cause you don't know how it's gonna be. Some sponsors recommend that you take the hardest, the one you're dreading the most-

A: Mhm.

L: ... and do that first cause then all the others are easy.

A: (laughs)

L: Um...s-I often recommend to my sponsees — and this is what I did — is I worked on the easiest ones, for me it was my kids. And I made an appointment with 'em individually and sat down. Um... and I knew they would forgive me and I knew that they would... understand, and I knew they were gonna say, "Oh, it's okay, mom" so those were less scary.

A: Mhm.

L: Uhm, but $\mathrm{i}-\{$ the all the fears come up all the fears that caused us to drink to begin with-

A: Mhm.

L: ... are what comes up when we're dealing with this-

A: Mhm.

L: ...because...that's part of the process, is - is walking through fears instead of going around them ADMITTING FEARS, BECOMING HONEST?.

A: Right.

L: You know, which is what we do as alcoholics when we're drinking.

A: Mhm.

L: We find the - the long way around-

A: Mhm. 
L: ...you know the painful...the short pain. Um, so... ya know for me it was very scary in the beginning.

A: Mhm.

L: I had some good ones and I had some bad ones-

A: Mhm.

L: ...you know.

A: Mhm.

L: \{And they're not ever over-I have a list that's always going...of amends that I need to make... and so I'm just-I continue to constantly make them, whenever the occasion arises CONSTANT PROCESS, LIFELONG \}.

A: Mhm. So is it easier as times goes on-

L: Yeah.

A: ...the more you do it-

L: Yeah.

A: ...does it just get easier.

L: It gets easier.

A: Does the fear decrease?

L: Somewhat.

A: Mhm.

L: Somewhat. As much as it can.

A: Mhm.

L: Um, I think when we have success with these, let's face it, it makes it easier.

A: Right.

L: Then we say the next one, "Oh, I can't wait to do the next one." One of the dangers though and - and I've noticed this in the ones I had that weren't so good, isis rushing this process. Doing it just because we're in the process and because we wanna get it done.

A: Mhm.

L: And if we rush it when we're not really ready and we're not ready, and the other person quite possibly isn't ready, \{cause it—it's worded in the step that - steps that we make amends except where it could harm others and we have to really look into, "Is this gonna harm the other person more than if I never said anything?"

A: Mhm.

L: And we don't try to figure that out on our own, again we work with our sponsors.

A: Mhm.

L: And our sponsors help us to decide whether it's a good idea or not a good idea

SPONSOR, PROGRAM RULES\}.

A: Mhm.

L: And so, ya know you go through...good and bad ones and ones that are more painful than others, but generally speaking, the other side is the Lest.

A: Mhm.

L: And it makes you wanna do more.

A: Mhm.

L: It makes you want to catapult into all of them.

A: Mhm.

L: Which can be dangerous. 
A: Mhm.

L: It can be very dangerous.

A: but it sounds like there's...there are a couple of people helping you through it. You have your sponsor, and then you have your higher power-

L: Mhm.

A: to-kind of maybe rely on to help you through?

L: \{Yeah, we always - we always invite the higher power in, um... and ask him toyou kn-we mediate about it, we stay quiet, and we ask him, "Is this good timing?"

A: Mhm.

L: You know, it's his will, and um... and then we just try to get answers. And if we don't get answers then we have to go through - through it without the fear. You know making very careful, very sure not to...make excuses why it's not a good time to make one HP AS GUIDE, PROGRAM RULES, MOVE AWAY FROM FEAR\}.

A: Mhm.

L: "I'm not getting a sign from God so I'm not gonna do that one today." -

A: (laughing)

L: is not a good excuse. Or...you know, or...uh, I'm tryna think of others... or 'I'm not sure if I can find that person". You know, there's a-there's a-a-a lot of excuses that we come up for, why we don't need to make these, but once we make 'em...they're...very rewarding.

A: Mhm.

L: And usually for both people.

A: Mhm.

L: Usually. Not always. but we don't wanna harm someone else, that's the important thing.

A: Right, right, right. So when you think about your good or successful amends, how or in what ways do they affect your relationship with yourself, your higher power, and the person accepting the amends?

L: For the good ones?

A: Yes, the good ones.

L: Well, cert—certainly helps self-esteem.

A: Mmm.

L: $\{$ It certainly makes you feel Letter about yourself and your sobriety. Um...it makes you understand why you're going through step 1-8 $\underline{\boldsymbol{S E L F}-\boldsymbol{E S T E E M}}$.

A: Mhm.

$\mathrm{L}:\{\mathrm{I}-\mathrm{i}-\mathrm{it}-\mathrm{it}$ connects the dots and it kind of...everything is full circle and you realize why...um, why it works because you're....uhh....you're cleaning house is what you're really doing. Um... and it's not enough to just to make an amend you have to clean house and then change your behavior, so it's a whole ball of wax that's kinda hard to... to put into words BEHAVIOR CHANGE, LIFELONG PROCESS\}, but....um...the good ones...not only help you, you hope that it's gonna help the other person. Again, we're not in the outcome business, but in most cases, it heals the relationship. You may not be best buds again, but - but it heals, there's a lot of healing goin' on. \{Mostly for you. And we're doing it for us. but-it - a lot of times it's for the others as well AMENDS FOR THE SELF\}.

A: Mhm. 
L: \{Ya know, it helps 'em to understand. but it does - it helps your self esteem, um..it makes you feel more comfortable and more confident in your day to day stuff $\underline{S E \boldsymbol{L F} \text { - }}$ ESTEEM, CONFIDENCE?. Um...it helps you to not beat yourself up. because a lot of...remorse comes out of getting sober. Ya know when we're drinking, when we're active, we don't have any remorse. You know, we don't really have any feelings at all \{we're just caught up in self-centeredness. And when we get sober, there's a lot of remorse for the things we did while we were drunk, and even when we're not drunk, just the way we lived. That dishonest life. Um..so, it—it's a healing process I guess is the best way I can explain it CHARACTER DEFECTS, REMORSE?.

A: Mhm.

L: It - it's like the beginning of a healing process.

A: And that-

L: If that makes sense. 


\section{BIBLIOGRAPHY}

Alcoholics Anonymous World Services, Inc. (2010). Alcoholics Anonymous: The story of how many thousands of men and women have recovered from alcoholism. New York, NY: Alcoholics Anonymous, Inc.

Atkins, R.G. \& Hawdon, J. E. (2007). Religiosity and participation in mutual-aid support groups for addiction. Journal of Substance Abuse Treatment, 33, 321331.

Brooks, A.J., \& Penn., P.E. (2003). Comparing treatments for dual diagnosis: Twelvestep and self-management and recovery training. The American Journal of Drug and Alcohol Abuse, 29(2), 359-383.

Cole, B.S., (2009). The process of cultural identity formation for African students studying in the U.S.: The 1.5 generation. (Unpublished Master's thesis). University of Rhode Island, Rhode Island.

Connors, J.G. \& Derman, K.H. (1996). Characteristics of participants in Secular Organizations for Sobriety. American Journal of Drug Alcohol Abuse 22(2), 281-295.

Enright, R.D., Santos, M.J.D., Al-Mabuk, R. (1989). The adolescent as the forgiver. Journal of Adolescence, 12, 95-110.

Gabhainn, S.N. (2003). Assessing sobriety and successful membership of Alcoholics Anonymous. Journal of Substance Use, 8, 55-61.

General Service Office of Alcoholics Anonymous (n.d.). A.A. Fact File. Retrieved February 2, 2012 from http://www.aa.org/pdf/products/m-24_aafactfile.pdf. 
Gomes, K., \& Hart, K.E. (2009). Adherence to recovery practices prescribed by Alcoholics Anonymous: Benefits to sustained abstinence and subjective quality of life. Alcoholism Treatment Quarterly, 27, 223-235.

Kaskutas, L., Turk, N., Bond, J., \& Weisner, C. (2003). The role of religion, spirituality and Alcoholics Anonymous in sustained sobriety. Alcoholics Treatment Quarterly, 21(1), 1-16.

Krause, N., \& Ellison, C.G. (2003). Forgiveness by God, forgiveness of others, and psychological well-being in late life. Journal for the Scientific Study of Religion, 42(1), 77-93.

Krentzman, A.R., Brower, K.J., Cranford, J.A., Bradley, J.C., \& Robinson, E.A.R. (2010). Gender and extroversions as moderators of the association between Alcoholics Anonymous and sobriety. Journal of Studies on Alcohol and Drugs, $73,44-52$.

Li, E.C., Feifer, C., \& Strohm, M. (2000). A pilot study: Locus of control and spiritual beliefs in Alcoholics Anonymous and smart recovery members. Addictive Behaviors, 25(4), 633-640.

Majer, J.M., Jason, L.A., Ferrari, J.R., \& Miller, S.A. (2011). 12-step involvement among a U.S. national sample of Oxford House residents. Journal of Substance Abuse Treatment 41, 37-44.

Marshall, M.N. (1996). Sampling in qualitative research. Oxford University Press, 13(6), 522-525.

McCrady, B. S., Horvath, A.T., \& Delaney, S. I. (2003). Self-help groups. In: R. K. Hester and W. R. Miller (Eds.), Handbook of alcoholism treatment 
approaches. Effective alternatives, Third Edition (pps. 165-187). Boston: Allyn \& Bacon.

McCullough, M.E., Worthington, E.L., \& Rachal, K.C. (1997). Interpersonal forgiving in close relationships. Journal of Personality and Social Psychology, 73(2), 321-336.

Miles, M.B. \& Huberman, A.M. (1994). An expanded sourcebook: Qualitative data analysis. Thousand Oaks, CA: SAGE Publications, Inc.

Morgenstern, J., Labouvie, E., McCrady, B. S., Kahler, C. W., Frey, R. M. (1997). Affiliation with Alcoholics Anonymous after treatment: A study of its therapeutic effects and mechanisms of action. Journal of Consult and Clinical Psychology, 65(5), 768-777.

Oakes, K.E., Allen, J.P., Ciarrocchi, J.W. (2000). Spirituality, religious problemsolving and sobriety in Alcoholics Anonymous. Alcoholism Treatment Quarterly, 18(2), 37-50.

Pagano, M.E., Zeltner, B.B., Jaber, J., Post, S.G., Zywiak, W.H., Stout, R.L. (2009). Helping others in long-term sobriety: Who should I help to stay sober? Alcoholism Treatment Quarterly, 27(1), 38-50.

Plano Clark, V.L. \& Creswell, J.W. (2010). Understanding research: A consumer's guide. Boston, MA: Merrill.

Robinson, E.A.R., Cranford, J.A., Webb, J.R., \& Brower, K.J. (2007). Six-month changes in spirituality, religiousness, and heavy drinking in a treatmentseeking sample. Journal on Studies on Alcohol, 68, 282-290. 
Sandelowski, M. (2000). Whatever happened to qualitative description? Research in Nursing and Health, 23, 334-340.

Shelton, Connecticut Step Meeting (2011). Personal inventory worksheets.

Tonigan, J.S., \& Rice, S.L. (2010). Is it beneficial to have an Alcoholics Anonymous sponsor? Psychology of Addictive Behaviors, 24(3), 397-403.

Wade, N.G., \& Worthington, E.L., Jr. (2003). Overcoming interpersonal offenses: Is forgiveness the only way to deal with unforgiveness? Journal of Counseling \& Development, 81, 343-355.

Wade, N. G., \& Worthington, E. L., Jr. (2005). In search of a common core: A content analysis of interventions to promote forgiveness. Psychotherapy: Theory, Research, Practice, Training, 42, 160-177.

Wade, N.G., Worthington, E.L. Jr., Haake, S. (2009). Comparison of explicit forgiveness interventions with an alternative treatment: A randomized clinical trial. Journal of Counseling and Development 87(2), 143-151.

Webb, J.R., Robinson, E.A.R., Brower, K.J., \& Zucker, R.A. (2006). Forgiveness and alcohol problems among people entering substance abuse treatment. Journal of Addictive Diseases, 25(3), 55-67.

Webb, J.R., Robinson, E.A.R., Brower, K.J. (2009). Forgiveness and mental health among people entering outpatient treatment with alcohol problems. Alcoholism Treatment Quarterly, 27, 368-388.

Weiner, B., Graham, S., Peter, O., \& Zmuidinas, M. (1991). Public confession and forgiveness. Journal of Personality, 59(2), 281-314. 
Worthington, E. L., Jr., \& Wade, N. G. (1999). The social psychology of unforgiveness and forgiveness and implications for clinical practice. Journal of Social and Clinical Psychology, 18, 385-418.

Zemore, S.E. (2007). A role for spiritual change in the benefits of 12-step involvement. Alcoholism: Clinical and Experimental Research, 31(3), 76-79. 